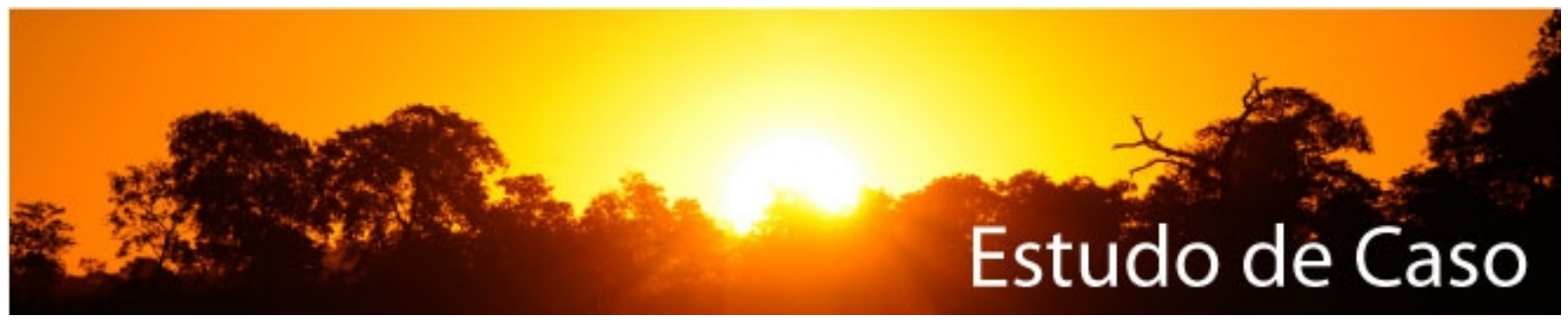

\title{
GERENCIAMENTO DE RESÍDUOS DO HOSPITAL MILITAR DE ÁREA DE BRASÍLIA
}

\author{
Weberson Roldão dos Santos ${ }^{1}$ \\ Jairo Afonso Henkes ${ }^{2}$
}

\begin{abstract}
RESUMO
A Gestão de Resíduos de Serviço de Saúde pode ser considerada como sendo um processo complexo de transformação, tanto no manejo efetivo destes resíduos em todas as etapas do processo, por parte de todos os profissionais diretamente ligados a ele, como na cultura organizacional que é necessária para a sua efetividade. 0 estabelecimento de um Plano de Gerenciamento de Resíduos de Serviço de Saúde em uma unidade hospitalar é fundamental para se minimizar os potenciais riscos à saúde da população e ao meio ambiente. O presente trabalho visa analisar 0 PGRSS implantado no Hospital Militar da Área de Brasília, procurando caracterizar sua estrutura e os tipos de serviços prestados à família militar da Guarnição de Brasília, com o objetivo de propor inovações e melhorias no mesmo, a fim de permitir o aprimoramento da gestão dos resíduos produzidos neste hospital, contribuindo assim para a melhoria da saúde da população e para preservação do meio ambiente.
\end{abstract}

Palavras-chave: Resíduos Sólidos, Resíduos Hospitalares, Plano de Gerenciamento de Resíduos.

- ${ }^{1}$ Acadêmico do Curso Superior de Tecnologia em Gestão Ambiental - Unisul Virtual. E-mail: weberson.santos@unisul.br

- $\quad 2$ Professor do Curso Superior de Tecnologia em Gestão Ambiental e do Programa de Pós Graduação em Gestão Ambiental da Unisul. Mestre em Agroecossistemas. Especialista em Administração Rural. E-mail: jairo.henkes@unisul.br 


\title{
1 INTRODUÇÃO
}

A geração de resíduos se confunde com a história da humanidade, pois desde a época do homem das cavernas havia produção de resíduos oriundos da alimentação, das atividades diárias, entre outras. Entretanto, a evolução da sociedade nos diversos setores, principalmente a partir de meados do século $X X$, proporcionou um aumento significativo da produção de resíduos, que começou a comprometer a saúde das pessoas e o meio ambiente (ANVISA, 2006).

\begin{abstract}
[...] Embora a geração de resíduos oriundos das atividades humanas faça parte da própria história do homem, é a partir da segunda metade do século $\mathrm{XX}$, com os novos padrões de consumo da sociedade industrial, que isso vem crescendo, em ritmo superior à capacidade de absorção pela natureza. Aliado a isso, o avanço tecnológico das últimas décadas, se, por um lado, possibilitou conquistas surpreendentes no campo das ciências, por outro, contribuiu para o aumento da diversidade de produtos com componentes e materiais de difícil degradação e maior toxicidade. (Manual de Gerenciamento de Resíduos do Serviço de Saúde, 2006).
\end{abstract}

Em vista disto a sociedade mundial vem se mobilizando para tentar reduzir os efeitos colaterais desta evolução, buscando melhorar o gerenciamento dos resíduos provenientes deste avanço tecnológico, a fim de evitar colocar em risco recursos naturais e a qualidade de vida das presentes e futuras gerações.

Conscientes da importância deste assunto, a sociedade mundial, por meio de seus representantes legais, vem adotando medidas no que concerne à preservação ambiental e consequentemente a melhoria da qualidade de vida da humanidade. Este movimento mundial está materializado por meio da criação de organismos internacionais de regulação e orientação, como exemplo tem-se a Organização Mundial de Saúde - OMS e a Organização Pana-Americana de Saúde - OPAS, que por intermédio de acordos, tratados e publicações orientam a comunidade mundial para procedimentos eticamente corretos e de conservação socioambiental. (OPAS, 1997).

Concorrente com este movimento mundial, as autoridades públicas vêm implantando políticas públicas e elaborando legislações, por meio de agências reguladoras e conselhos, como a Agência Nacional de Vigilância Sanitária - ANVISA e o Conselho Nacional de Meio Ambiente - CONAMA, com o objetivo de se buscar o desenvolvimento sustentável e a preservação da saúde coletiva. 
Diante deste cenário pode se mostrar a responsabilidade assumida pelos dois órgãos citados acima, que editaram publicações com vistas a melhorar o gerenciamento de resíduos dos serviços de saúde, quais sejam: a Resolução da Diretoria Colegiada/RDC 306 ANVISA, de 2004, e a Resolução CONAMA 358, de 2005. (ANVISA, 2006).

Fruto desta conscientização iniciada pelos órgãos reguladores incentivou-se os profissionais da área de saúde e seus gestores a adotarem medidas com vista a proteger o meio ambiente e a saúde da população, em função da consciência de que os resíduos gerados pelos serviços de saúde podem causar danos irreparáveis se mal geridos.

Apesar disso e do esforço desprendido pelos profissionais que trabalham no HMAB, a gestão integrada de resíduos de serviços de saúde ainda é incipiente, em virtude de ser um assunto extremamente moderno e atual, carecendo de aprimoramento por parte não só dos profissionais de saúde, mas também dos órgãos públicos em geral que ainda têm grandes dificuldades no trato com este assunto.

A RDC 306 ANVISA, de 2004, e a resolução CONAMA 358, de 2005, apesar de serem normas recentes sofreram aprimoramentos, em função da publicação da LEI No 12.305, de 2 de agosto de 2010, que institui a Política Nacional de Resíduos Sólidos, que altera a Lei no 9.605, de 12 de fevereiro de 1998. Estas alterações constantes dificultam o amadurecimento dos processos que envolvem o gerenciamento de resíduos de saúde.

As duas normas vigentes, a RDC 306 ANVISA, de 2004, e a resolução CONAMA 358, de 2005, determinam que todos os serviços de saúde devem adotar um Plano de Gerenciamento de Resíduos de Serviços de Saúde (PGRSS), a ser submetido à aprovação pelos órgãos de meio ambiente federal, estadual e municipal e de vigilância sanitária, dentro de suas respectivas esferas de competência. Este plano deverá conter todas as ações e rotinas que devam ser adotadas pelos gestores de saúde, contemplando os aspectos que vão desde a geração, passando pela segregação, acondicionamento, coleta, armazenamento, transporte, tratamento, até a disposição final dos resíduos produzidos. (ANVISA, 2006). 


\section{TEMA}

A geração de resíduos é uma temática que está presente desde a formação da sociedade como a conhecemos. Com o passar do tempo esta relação se tornou ainda maior e complexa, sendo necessária a criação de dispositivos que controlasse o seu crescimento. No Brasil temos legislações específicas que tratam sobre este assunto, como a lei $n^{\circ} 12.305$, de 02 de agosto de 2010, que institui a Política Nacional de Resíduos Sólidos. Esta lei dispõe sobre a gestão integrada e o gerenciamento de resíduos sólidos no país, incluindo os perigosos. Dispõe também sobre as responsabilidades dos geradores e do poder público e aos instrumentos econômicos aplicáveis.

Para uma compreensão melhor, a Política Nacional de Resíduos Sólidos define resíduos como sendo,

[...] material, substância, objeto ou bem descartado resultante de atividades humanas em sociedade, a cuja destinação final se procede, se propõe proceder ou se está obrigado a proceder, nos estados sólido ou semissólido, bem como gases contidos em recipientes e líquidos cujas particularidades tornem inviável o seu lançamento na rede pública de esgotos ou em corpos d'água, ou exijam para isso soluções técnica ou economicamente inviáveis em face da melhor tecnologia disponível.

Neste contexto, este trabalho irá tratar como tema o gerenciamento de resíduos feito pelo Hospital Militar de Área de Brasília (HMAB). Em especial, os resíduos do serviço de saúde (RSS). Por ser uma Unidade de Saúde esta é regida pela Resolução da Diretoria Colegiada/RDC 306 ANVISA, de 2004, e a Resolução CONAMA 358, de 2005.

Apesar de estas normas serem editadas por organismos distintos, estas publicações encerram objetivos comuns de preservação ambiental e melhoria da qualidade da saúde da população, como se pode observar.

\footnotetext{
"A Resolução CONAMA no 358/05 trata do gerenciamento sob o prisma da preservação dos recursos naturais e do meio ambiente. Promove a competência aos órgãos ambientais estaduais e municipais para estabelecerem critérios para o licenciamento ambiental dos sistemas de tratamento e destinação final dos RSS."

"Por outro lado, a RDC ANVISA no 306/04 concentra sua regulação no controle dos processos de segregação, acondicionamento, armazenamento, transporte, tratamento e disposição final. Estabelece procedimentos operacionais em função dos riscos envolvidos e concentra seu controle na inspeção dos serviços de saúde."
} 
Por ser um gerador de resíduos de serviços de saúde, o HMAB, conforme previsto na Resolução CONAMA n 358/05 e na RDC ANVISA n 306/04, deve elaborar e implantar um Plano de Gerenciamento de Resíduos de Serviços de Saúde PGRSS. A Resolução CONAMA n 358/05 define um PGRSS como,

[...] documento integrante do processo de licenciamento ambiental, baseado nos princípios da não geração de resíduos e na minimização da geração de resíduos, que aponta e descreve as ações relativas ao seu manejo, no âmbito dos serviços de saúde, contemplando os aspectos referentes à geração, segregação, acondicionamento, coleta, armazenamento, transporte, reciclagem, tratamento e disposição final, bem como a proteção à saúde pública e ao meio ambiente.

Já conforme o Manual de Gerenciamento de Resíduos do Serviço de Saúde (2006, p.64) um PGRSS é,

[...] documento que aponta e descreve as ações relativas ao manejo dos resíduos sólidos, observadas suas características e riscos, no âmbito dos estabelecimentos, contemplando os aspectos referentes à geração, segregação, acondicionamento, coleta, armazenamento, transporte, tratamento e disposição final, bem como as ações de proteção à saúde e ao meio ambiente.

Verificando as definições constatamos que um PGRSS tem por objetivo principal proteger a saúde de todas as pessoas, melhorando com isso a qualidade de vida dos profissionais e pacientes, e também, busca diminuir os impactos ambientais proveniente dos resíduos produzidos. Como previsto e determinado em lei o HMAB possui implantado um Plano de Gerenciamento de Resíduos de Serviços de Saúde. Entretanto, fruto de observações e entrevistas realizadas durante a semana de imersão, e de diversas visitas realizadas naquela unidade de saúde, observaramse diversas oportunidades de inovação e melhoria do plano existente. Especialmente, com vistas a aprimorar os métodos de coleta seletiva e minimizar os riscos oferecidos ao meio ambiente e aos usuários, oriundos dos resíduos hospitalares.

Logo, seria possível o aperfeiçoamento deste PGRSS, diminuindo ainda mais os possíveis impactos causados na sua destinação final? Visando aprimorar o gerenciamento dos resíduos produzidos no HMAB, principalmente dar a adequada destinação final aos resíduos produzidos pelos diversos setores do hospital, este trabalho pretende apresentar propostas de inovação e melhoria. Estas propostas ao PGRSS existente, além de minimizar os riscos provenientes dos resíduos de saúde, buscará reduzir o desperdício de material e equipamento gastos na gestão dos resíduos e com isso evitar causar danos à saúde das pessoas e ao meio ambiente no qual esta unidade de saúde está inserida. 


\section{OBJETIVOS}

\subsection{OBJETIVO GERAL}

Analisar o PGRSS do HMAB e propor ações de inovação e melhoria neste, com fulcro na minimização da produção de resíduos, bem como proporcionar um encaminhamento seguro dos resíduos gerados.

\subsection{OBJETIVOS ESPECÍFICOS}

-Propor medidas técnicas para reduzir o potencial de infecção no ambiente de trabalho e o impacto ambiental durante o transporte interno e externo e, ainda, nos locais de tratamento e armazenamento intermediário e final.

-Despertar o interesse de todos pela correta gestão dos resíduos produzidos naquela unidade de saúde.

-Analisar o PGRSS implantado no HMAB de forma a identificar os tipos e a quantidade de resíduos produzidos, os locais de geração e a forma de tratamento até a destinação final.

-Analisar a legislação pertinente à gestão de resíduos de saúde, comparando à realidade do HMAB.

-Propor inovações e melhorias no PGRSS do HMAB, condizentes com suas peculiaridades e conforme a legislação específica, com vistas a, diminuição da produção de resíduos e, consequentemente, de riscos à saúde da população e ao meio ambiente.

\section{PROCEDIMENTOS METODOLÓGICOS}

\subsection{CAMPO DE ESTUDO}

A caracterização do estudo deste trabalho será uma pesquisa na forma de um estudo de caso EXPLORATÓRIO. Com base na explicação de Rauen (2002) que, mostra o estudo de caso como um estudo profundo de um ou de poucos obje- 
tos, que busca retratar a realidade de forma completa e profunda, de modo a permitir o seu amplo e detalhado conhecimento.

O Universo desta pesquisa compreende o Hospital Militar de Área de Brasília (HMAB) que tem como missão presta assistência primária e secundária de saúde aos militares do Exército, pensionistas, dependentes e servidores civis. O HMAB tem sede na Quadra Residencial de Oficiais, Setor Militar Urbano, na cidade de Brasília - DF. Possui um quadro de funcionários de 600 (seiscentos) militares que englobam os da área de saúde os que trabalham em setores administrativos e com 172 (cento e setenta e dois) servidores civis, englobando também a área médica e administrativa.

A escolha da amostra nesta pesquisa será de caráter não probabilístico, por entender que a natureza do problema implica a escolha de sujeitos com características definidas pelo pesquisador, o qual escolheu como amostra o responsável pelo Plano de Gerenciamento de Resíduos de Serviço de Saúde do HMAB.

\subsection{INSTRUMENTOS DE COLETA DE DADOS}

Os instrumentos de coleta de dados adotados neste trabalho são descritos no quadro a seguir. 


\begin{tabular}{|c|c|c|}
\hline $\begin{array}{l}\text { Instrumento de } \\
\text { coleta de dados }\end{array}$ & Universo pesquisado & Finalidade do Instrumento \\
\hline Entrevista & $\begin{array}{l}\text { - Gestor de Resíduos de Saú- } \\
\text { de do Hospital Militar de Área } \\
\text { de Brasília (HMAB) } \\
\text { - Outros Profissionais que atu- } \\
\text { am no HMAB }\end{array}$ & $\begin{array}{l}\text { Tem por finalidade colher } \\
\text { informações básica de todos } \\
\text { os procedimentos de geren- } \\
\text { ciamento de resíduos desta } \\
\text { unidade de saúde. }\end{array}$ \\
\hline $\begin{array}{l}\text { Observação Di- } \\
\text { reta do partici- } \\
\text { pante }\end{array}$ & $\begin{array}{l}\text { Observação in loco de vários } \\
\text { setores do HMAB, laboratórios, } \\
\text { consultórios médicos e odonto- } \\
\text { lógicos, ambulatório, pronto } \\
\text { atendimento, farmácia, etc. }\end{array}$ & $\begin{array}{l}\text { Estas observações têm como } \\
\text { objetivo verificar se todos os } \\
\text { procedimentos previstos no } \\
\text { Plano de Gerenciamento de } \\
\text { Resíduos de Saúde estão } \\
\text { sendo adotados corretamen- } \\
\text { te. Além disso, constituir me- } \\
\text { lhorias dos processos utiliza- } \\
\text { dos da geração a destinação } \\
\text { final dos resíduos. }\end{array}$ \\
\hline Documentos & $\begin{array}{l}\text { - Plano de Gerenciamento de } \\
\text { Resíduos do Serviço de Saú- } \\
\text { de; } \\
\text { - Bibliografias sobre o tema, } \\
\text { Artigos científicos, sites e Re- } \\
\text { latórios relativos ao RSSS. }\end{array}$ & Buscar embasamento teórico. \\
\hline
\end{tabular}

Quadro 1- Instrumento de coleta de dados.

Fonte: Unisul Virtual, 2007. 


\section{APRESENTAÇÃO E ANÁLISE DA REALIDADE OBSERVADA}

\subsection{GESTÃO DE RESÍDUOS SÓLIDOS}

A gestão de qualquer processo é fundamental para o seu aprimoramento e para a obtenção de bons resultados, com o gerenciamento de resíduos não poderia ser diferente, como é citado no Manual de Gerenciamento de Resíduos de Saúde da ANVISA.

[...] A importância da gestão. A gestão compreende as ações referentes às tomadas de decisões nos aspectos administrativo, operacional, financeiro, social e ambiental e tem no planejamento integrado um importante instrumento no gerenciamento de resíduos em todas as suas etapas - geração, segregação, acondicionamento, transporte, até a disposição final, possibilitando que se estabeleçam de forma sistemática e integrada, em cada uma delas, metas, programas, sistemas organizacionais e tecnologias, compatíveis com a realidade local a boa gestão impactará em vários aspectos. (Manual de gerenciamento de resíduos de serviços de saúde, 2006.).

Como citado acima à gestão se faz importante em diversos aspectos, que inclui o econômico. Ao se gerenciar os resíduos produzidos, pode-se mensurar com mais precisão os materiais e equipamentos que são necessários ao seu processamento, evitando compras e gastos desnecessários. Além do mais, ao se gerenciar a produção de resíduos, pode-se obter informações importantes para a tomada de decisão, no que concerne a recuperá-los, reciclá-los ou transportá-los, verificando-se a melhor opção econômica como referenciado no manual da Organização PanAmericana de Saúde (OPAS).

[...] Quando o custo de recuperação dos resíduos é mais econômico que seu transporte, tratamento e/ou disposição adequada, os responsáveis pelo manuseio desses resíduos optarão por assegurar a reciclagem. (Manual para o Manejo Interno de Resíduos Sólidos em Estabelecimentos de Saúde, 1997.).

Ressaltasse ainda no manual da ANVISA que, uma das vantagens da segregação de resíduos é "Diminuir gastos, já que apenas terá tratamento especial uma fração e não todos.". 
No gerenciamento de resíduos uma das ações mais importantes é a segregação, com vistas à obtenção de resultados satisfatórios deste processo, como consta do manual da OPAS.

[...] A segregação é uma das operações fundamentais para permitir o cumprimento dos objetivos de um sistema eficiente de manuseio de resíduos e consiste em separar ou selecionar apropriadamente os resíduos segundo a classificação adotada. Essa operação deve ser realizada na fonte de geração, condicionada à prévia capacitação do pessoal de serviço. (Manual para o Manejo Interno de Resíduos Sólidos em Estabelecimentos de Saúde, 1997.).

O mesmo manual da OPAS lista algumas vantagens da segregação, que é uma operação do gerenciamento de resíduos, dentre elas a redução dos riscos à saúde, estando diretamente relacionado à segurança de pessoas e do meio ambiente.

[...] Reduzir os riscos para a saúde e o ambiente, impedindo que os resíduos infecciosos ou especiais, que geralmente são frações pequenas, contaminem os outros resíduos gerados no hospital. (Manual para o Manejo Interno de Resíduos Sólidos em Estabelecimentos de Saúde, 1997.).

Além disso, a Resolução RDC 306, de 7 de dezembro de 2004, em seu capítulo IV, elenca os cuidados necessários com a segurança ocupacional e com a higiene, ou seja, do pessoal diretamente envolvido com o manejo de resíduos hospitalares, sendo favorável à segurança, dos usuários e toda a sociedade.

[...] As medidas de higiene e segurança permitirão que o pessoal, além de proteger sua própria saúde, desenvolva com maior eficiência seu trabalho. Tais medidas incluem aspectos de capacitação no trabalho, conduta apropriada, disciplina, higiene e proteção pessoal, entre outras, e são complementares às ações desenvolvidas no ambiente de trabalho, como iluminação, ventilação, ergonomia, etc. (RDC 306 ANVISA, 2004).

A gestão de resíduos tem como um de seus objetivos a preservação do meio ambiente, pois, se classifica tanto na Resolução RDC 306, de 7 de dezembro de 2004, quanto no manual da OPAS, os resíduos por categoria, determinando-se os cuidados necessários ao seu manejo como sua destinação final, com vistas à preservação do meio ambiente, sendo necessário licenciamento ambiental dos aterros sanitários que receberão os resíduos produzido, conforme preconiza as Resoluções do Conselho Nacional de Meio Ambiente (CONAMA) N 001/86 e 237/97.

Cita-se também no manual de gerenciamento de Resíduos de Saúde da ANVISA o seguinte:

[...] A Lei de Política Nacional do Meio Ambiente (Lei n o 6.938/81), no seu artigo $3^{\circ}$, e a Lei dos Crimes Ambientais (Lei № 9.605/98), artigos 54 e 56, 
responsabilizam administrativa, civil e criminalmente as pessoas físicas e jurídicas, autoras e coautoras de condutas ou atividades lesivas ao meio ambiente. Com isso, as fontes geradoras ficam obrigadas a adotar tecnologias mais limpas, aplicar métodos de recuperação e reutilização sempre que possível, estimular a reciclagem e dar destinação adequada, incluindo transporte, tratamento e disposição final. (Manual de gerenciamento de resíduos de serviços de saúde, 2006.).

Mesmo com a existência de dispositivos legais à preservação ambiental e a adoção de um sistema de gerenciamento de resíduos, ainda ocorrem fatos desagradáveis de degradação do meio ambiente como, por vezes são relatados na mídia.

O não gerenciamento de resíduos, em especial, os de saúde, poderá trazer danos aos usuários do sistema de saúde como para toda a população circunvizinha a uma Organização de Saúde, que são definidas pela Resolução RDC 306, de 7 de dezembro de 2004.

[...] Este Regulamento aplica-se a todos os geradores de Resíduos de Serviços de Saúde-RSS. Para efeito deste Regulamento Técnico, definem-se como geradores de RSS todos os serviços relacionados com o atendimento à saúde humana ou animal, inclusive os serviços de assistência domiciliar e de trabalhos de campo; laboratórios analíticos de produtos para saúde; necrotérios, funerárias e serviços onde se realizem atividades de embalsamamento (tanatopraxia e somatoconservação); serviços de medicina legal; drogarias e farmácias inclusive as de manipulação; estabelecimentos de ensino e pesquisa na área de saúde; centros de controle de zoonoses; distribuidores de produtos farmacêuticos, importadores, distribuidores e produtores de materiais e controles para diagnóstico in vitro; unidades móveis de atendimento à saúde; serviços de acupuntura; serviços de tatuagem, dentre outros similares. (RDC 306 ANVISA, 2004).

O cuidado com a gestão de resíduos de saúde evitar-se-á proliferação de doenças e contaminação advinda dos mesmos, ainda, de vetores como roedores e insetos que poderão causar danos à saúde da população.

\subsection{RESÍDUOS SÓLIDOS}

Têm-se várias denominações e classificações para os resíduos sólidos, entretanto tomou-se por base as considerações realizadas pelo CONAMA, como se vê.

A Resolução CONAMA n 005/1993 define resíduos sólidos como: resíduos nos estados sólido e semissólido que resultam de atividades de origem industrial, doméstica, hospitalar, comercial, agrícola e de serviços de varri- 
ção. Ficam incluídos nesta definição os lodos provenientes de sistemas de tratamento de água, aqueles gerados em equipamentos e instalações de controle de poluição, bem como determinados líquidos cujas particularidades tornem inviável o seu lançamento na rede pública de esgotos ou corpos de água, ou exijam para isso soluções técnica e economicamente inviáveis em face à melhor tecnologia disponível.

Conforme definição acima se pode inferir que resíduos sólidos abrangem não só os que se encontram no estado sólido. No entanto, como se baseou nas normas e resoluções em vigor do CONAMA e da ANVISA, a classificação dos resíduos sólidos é em função dos riscos potenciais ao meio ambiente e à saúde, como também, em função da natureza e origem, orientada pelas atribuições e responsabilidades de cada um destes órgãos, nas quais estão referenciados os resíduos de Serviço de saúde, pela sua origem.

Neste contexto os resíduos sólidos são classificados em: domiciliar, comercial, varrição e feiras livres, serviços de saúde, portos, aeroportos e terminais rodoviários e ferroviários, industriais, agrícolas e resíduos de construção civil.

As normas reguladoras agrupam os resíduos sólidos em relação à responsabilidade pelo gerenciamento, em dois grandes grupos. O primeiro grupo referese aos resíduos sólidos urbanos, compreendendo: os resíduos domésticos ou residenciais; os resíduos comerciais; os resíduos públicos. O segundo grupo, dos resíduos de fontes especiais, abrangendo: os resíduos industriais; os resíduos da construção civil; os rejeitos radioativos; os resíduos de portos, aeroportos e terminais rodoferroviários; os resíduos agrícolas; os resíduos de serviços de saúde.

\subsection{RESÍDUOS DO SERVIÇO DE SAÚDE}

\subsubsection{Definição}

Conforme estabelecido na RDC ANVISA 306/04 e na Resolução CONAMA 358/05, os resíduos de serviço de saúde são os gerados na prestação dos seguintes serviços:

[...] os serviços relacionados com o atendimento à saúde humana ou animal, inclusive os serviços de assistência domiciliar e de trabalhos de campo; laboratórios analíticos de produtos para a saúde; necrotérios, funerárias e serviços onde se realizem atividades de embalsamamento, serviços de medicina legal, drogarias e farmácias inclusive as de manipulação; estabelecimentos de ensino e pesquisa na área da saúde, centro de controle de zoonoses; distribuidores de produtos farmacêuticos, importadores, distri- 
buidores produtores de materiais e controles para diagnóstico in vitro, unidades móveis de atendimento à saúde; serviços de acupuntura, serviços de tatuagem, dentre outros similares. (Resolução CONAMA 358, 2005)

\subsubsection{Classificação}

A RDC ANVISA 306/04 e a Resolução CONAMA 358/05, classificam os RSS em função de suas características e dos seus potenciais riscos ao meio ambiente e à saúde das pessoas. Os RSS são classificados em cinco grupos: A, B, C, D e E, como descrito abaixo:

- Grupo A - engloba os componentes com possível presença de agentes biológicos que, por suas características de maior virulência ou concentração, podem apresentar risco de infecção. Exemplos: placas e lâminas de laboratório, carcaças, peças anatômicas, tecidos, bolsas transfusionais contendo sangue, dentre outras.

- Grupo B - contém substâncias químicas que podem apresentar risco à saúde pública ou ao meio ambiente, dependendo de suas características de inflamabilidade, corrosividade, reatividade e toxicidade. Ex: medicamentos apreendidos, reagentes de laboratório, resíduos contendo metais pesados, dentre outros.

- Grupo C - quaisquer materiais resultantes de atividades humanas que contenham radionuclídeos em quantidades superiores aos limites de eliminação especificados nas normas da Comissão Nacional de Energia Nuclear - CNEN, como, por exemplo, serviços de medicina nuclear e radioterapia etc.

- Grupo D - não apresentam risco biológico, químico ou radiológico à saúde ou ao meio ambiente, podendo ser equiparados aos resíduos domiciliares. Ex: sobras de alimentos e do preparo de alimentos, resíduos das áreas administrativas etc.

- Grupo E - materiais perfuro cortantes ou escarificantes, tais como lâminas de barbear, agulhas, ampolas de vidro, pontas diamantadas, lâminas de bisturi, lancetas, espátulas e outros similares.

Em função dos riscos potenciais os RSS devem ser manuseados e trata- 
dos de forma distinta, a fim de se evitar acidentes com consequentes danos ao meio ambiente e as pessoas.

\subsection{PLANO DE GERENCIAMENTO DE RESÍDUOS DOS SERVIÇOS DE SAÚDE (PGRSS)}

A resolução RDC 306 ANVISA de 2004, que dispõe sobre o Regulamento Técnico para o gerenciamento de resíduos de serviços de saúde e a resolução CONAMA 358 de 2005, que Dispõe sobre o tratamento e a disposição final dos resíduos dos serviços de saúde, definem o que são serviços de saúde, para definir sua abrangência.

O Art. $1^{\circ}$ da resolução CONAMA 358 de 2005, encerra o seguinte:

[...] Art. 1 o Esta Resolução aplica-se a todos os serviços relacionados com o atendimento à saúde humana ou animal, inclusive os serviços de assistência domiciliar e de trabalhos de campo; laboratórios analíticos de produtos para saúde; necrotérios, funerárias e serviços onde se realizem atividades de embalsamamento (tanatopraxia e somatoconservação); serviços de medicina legal; drogarias e farmácias inclusive as de manipulação; estabelecimentos de ensino e pesquisa na área de saúde; centros de controle de zoonoses; distribuidores de produtos farmacêuticos; importadores, distribuidores e produtores de materiais e controles para diagnóstico in vitro; unidades móveis de atendimento à saúde; serviços de acupuntura; serviços de tatuagem, entre outros similares. [...]

A resolução RDC 306 ANVISA de 2004, define o seguinte:

[...] Este Regulamento aplica-se a todos os geradores de Resíduos de Serviços de Saúde-RSS. Para efeito deste Regulamento Técnico, definem-se como geradores de RSS todos os serviços relacionados com o atendimento à saúde humana ou animal, inclusive os serviços de assistência domiciliar e de trabalhos de campo; laboratórios analíticos de produtos para saúde; necrotérios, funerárias e serviços onde se realizem atividades de embalsamamento (tanatopraxia e somatoconservação); serviços de medicina legal; drogarias e farmácias inclusive as de manipulação; estabelecimentos de ensino e pesquisa na área de saúde; centros de controle de zoonoses; distribuidores de produtos farmacêuticos, importadores, distribuidores e produtores de materiais e controles para diagnóstico in vitro; unidades móveis de atendimento à saúde; serviços de acupuntura; serviços de tatuagem, dentre outros similares. [...]

Como se vê acima, o que determina estas duas normas abrange uma unidade hospitalar. Estas mesmas normas preveem a obrigatoriedade de adoção de um Plano de Gerenciamento de resíduos de Serviço de Saúde por parte de uma unidade de saúde, como materializado abaixo. 
[...] Art. 3 o Cabe aos geradores de resíduos de serviço de saúde e ao responsável legal, referidos no art. 1 desta Resolução, o gerenciamento dos resíduos desde a geração até a disposição final, de forma a atender aos requisitos ambientais e de saúde pública e saúde ocupacional, sem prejuízo de responsabilização solidária de todos aqueles, pessoas físicas e jurídicas que, direta ou indiretamente, causem ou possam causar degradação ambiental, em especial os transportadores e operadores das instalações de tratamento e disposição final, nos termos da Lei n o 6.938, de 31 de agosto de 1981 [...] (Resolução CONAMA 358 de 2005).

[...] Compete aos serviços geradores de RSS: [...] 2.1. A elaboração do Plano de Gerenciamento de Resíduos de Serviços de Saúde - PGRSS, obedecendo a critérios técnicos, legislação ambiental, normas de coleta e transporte dos serviços locais de limpeza urbana e outras orientações contidas neste Regulamento. [...] (RDC 306 ANVISA de 2004).

É lícito supor, fruto do que abordado acima, que tanto a resolução RDC 306 ANVISA de 2004, quanto à resolução CONAMA 358 de 2005, ambas determina a obrigatoriedade de implantação de um PGRSS por parte de todos os geradores de RSS, que inclui um hospital.

\subsection{ETAPAS DO GERENCIAMENTO}

O gerenciamento de resíduos do serviço de saúde é realizado em dez etapas: manejo, segregação, acondicionamento, identificação, transporte interno, armazenamento temporário, tratamento, armazenamento externo, coleta e transporte externo e disposição final. (RDC n 306, 2004).

\subsubsection{Manejo}

O manejo dos RSS compreende todas as ações e tarefas integrantes do processo de gerenciamento dos resíduos, desde a sua geração, dentro do estabelecimento de saúde, até sua disposição final, realizada externamente ao mesmo.

\subsubsection{Segregação}

Pode ser entendida como sendo uma atividade de separação dos RSS por classes, segundo determina as Resoluções 306 ANVISA e 358 CONAMA, no momento de sua geração, considerando suas características físicas, químicas, biológicas, estado físico e os riscos advindos dos mesmos. 


\subsubsection{Acondicionamento}

É a ação de embalar os resíduos já segregados, em recipientes adequados ao seu peso e volume, conforme sua classificação e de acordo com as NBR 9191/2000 da ABNT e RDC 306 ANVISA, a fim de impedir vazamentos e resistam às ações de punctura e ruptura.

\subsubsection{Identificação}

É o conjunto de medidas que permite aos profissionais que manuseiam os RSS reconhecerem a classe a qual pertencem, possibilitando obter informações necessárias ao correto manejo dos resíduos. Esta identificação deve seguir as orientações contidas na RDC 306 ANVISA e seguir a padronização contida nas NBR 7.500 da $A B N T$, que determina o tipo de identificação que cada classe de resíduo deverá ter.

\subsubsection{Transporte Interno}

O transporte interno consiste em trasladar os resíduos dos locais de geração até área destinada ao seu armazenamento temporário ou diretamente para a área do armazenamento externo, com o intuito de viabilizar a sua coleta. Esta atividade deve seguir as orientações contidas na RDC 306 ANVISA que orienta como deverá ser realizada essa atividade, a fim de se evitar riscos a todos que se utilizam do serviço da unidade hospitalar.

\subsubsection{Armazenamento temporário}

O armazenamento temporário caracteriza-se pela guarda temporária dos recipientes contendo os resíduos já segregados e embalados, em uma área para isso destinada, em um local interno da unidade hospitalar, próximo do ambiente de geração dos RSS, com o objetivo de agilizar a coleta dos mesmos e agilizar o transporte para o ponto destinado à coleta externa. Esta atividade segue orientações contidas nas RDC 306 ANVISA e deve cumprir o que prescreve a NBR 12235 da ABNT. 


\subsubsection{Tratamento}

É o método, técnica de processo que modifique as características dos RSS, a fim de minimizar os riscos inerentes aos mesmos, reduzindo ou eliminando a possibilidade de contaminação, de acidentes ocupacionais ou de dano ao meio ambiente. Este procedimento pode ser aplicado no próprio estabelecimento gerador ou em outro estabelecimento, observadas nestes casos, as condições de segurança para o transporte entre o estabelecimento gerador e o local do tratamento. Os métodos de tratamento a serem aplicados nos resíduos de serviços de saúde, devem ser objeto de licenciamento ambiental, de acordo com a Resolução CONAMA n. 237/1997 e são passíveis de fiscalização e de controle pelos órgãos de vigilância sanitária e de meio ambiente.

\subsubsection{Armazenamento Externo}

Este procedimento consiste no acondicionamento dos recipientes de RSS até a próxima atividade, que é a coleta externa. Este local deve ser um ambiente exclusivo, deve permitir com facilidade o acesso dos veículos coletores. Nesta área não deve ser permitido à manutenção das embalagens que contenham RSS fora de seus recipientes.

\subsubsection{Coleta e Transporte Externo}

Esta atividade é caracterizada pela remoção dos RSS do local de armazenamento externo até a área de tratamento ou disposição final, que deve ser realizada utilizando-se técnicas que garantam a preservação das condições de acondicionamento e a integridade dos trabalhadores, da população e do meio ambiente. Os procedimentos desta ação devem estar de acordo com as orientações dos órgãos de limpeza urbana regional e atender as normas NBR 12.810 e NBR 14652 da ABNT. 


\subsubsection{Disposição Final}

Este procedimento se caracteriza pela disposição dos RSS em local adequado, como aterros sanitários, ou em locais de incineração, devidamente licenciados segundo as normas ambientais e de acordo a Resolução CONAMA n 237/97.

\subsection{CARACTERIZAÇÃO DO HOSPITAL MILITAR DE ÁREA DE BRASÍLIA}

\subsubsection{Subordinação}

Administrativamente é subordinado ao Comando da $11^{\text {a }}$ Região Militar e Tecnicamente à Diretoria de Saúde / D-Sau, ambas com sede em Brasília-DF, (HMAB, 2012).

\subsubsection{Missão}

Prestar assistência primária e secundária de saúde aos militares do Exército, pensionistas, dependentes e servidores civis, bem como proporcionar educação continuada em saúde. (HMAB, 2012).

\subsubsection{Recursos Humanos}

O HMAB conta em seus quadros com 600 (seiscentos) militares que englobam os da área de saúde, os que trabalham em setores administrativos, conta ainda com 172 (cento e setenta e dois) servidores civis, envolvendo também a área médica e administrativa. (HMAB, 2012).

\subsection{4 Área Física}

O HMAB possui cerca de $1.675 .000 \mathrm{~m}^{2}$ (um milhão seiscentos e setenta e cinco mil) metros quadrados de área construída, estando encravado entre duas Organizações Militares-OM de Brasília, não sendo possível ampliar horizontalmente 
suas instalações, sendo um óbice para a melhoria dos serviços por ela prestados. (HMAB, 2012).

\subsubsection{Localização}

Localiza-se no Setor Militar Urbano, próximo ao Quartel General do Exército e da grande maioria das OM da Guarnição de Brasília, sendo um fator positivo para a rápida evacuação de feridos para o hospital. (HMAB, 2012).

\subsubsection{Público Alvo}

Atende a todos os militares da ativa e da reserva e servidores civis da área da $11^{\text {a }} \mathrm{RM}$, que engloba os estados do Tocantins, Goiás e Distrito Federal, perfazendo um total de cerca de 70.000 (setenta mil) usuários. (HMAB, 2012).

\subsubsection{Tipos de Atendimentos}

Possui enfermaria, ambulatório, Unidade de Cuidados Intensivos e emergência.

O atendimento médico conta com aproximadamente, 25 (vinte e cinco) especialidades. Ainda assim, possui carência nas seguintes especialidades: Dermatologia, Oncologia, Gastroenterologia, Neurologia, Reumatologia, Nefrologia, Psiquiatria, Pneumologia, Hematologia, Infectologia e Intensivista.

O atendimento odontológico é realizado em cerca de 8 (oito) especialidades: Endodontista, Ortodontista, Pereodontista, Cirúrgica, Protética, Pediátrica e Implantodontista.

Serviços de imagem (ressonância magnética e raios- $X$ ), realização de exames de laboratório, serviço de quimioterapia oncológica e realiza ainda cirurgias de facectomias com implante de lente intraocular. (HMAB, 2012). 


\subsection{ANÁLISE DO PGRSS}

\subsubsection{Considerações Iniciais sobre o PGRSS do HMAB}

A presente proposta baseou-se na análise do PGRSS do HMAB, com base em entrevistas e visitas realizadas nos diversos setores do hospital, bem como na aplicação da legislação que regulamenta a gestão de resíduos de serviço de saúde.

No PGRSS implantado pela instituição não há menção de uma forma regular de difusão deste plano, como prevê o Manual de Gerenciamento de Resíduos de Serviço de Saúde da ANVISA. Seria interessante também que houvesse orientações informando para quais setores foi ou deveria ser difundido o PGRSS.

No PGRSS analisado não há indicação dos custos relacionados ao gerenciamento dos RSS do HMAB, a referência que há é o $n^{\circ}$ do contrato com a empresa que realiza a coleta externa e a destinação final. Há que se considerar a importância da gestão dos custos relacionados com o processo de gestão dos RSS.

No item 2 do PGRSS do HMAB é identificada a equipe de implantação, entretanto, não há indicação do setor do hospital eles pertencem, visando à comprovação de que todos que geram RSS estão envolvidos no processo de implantação e gestão dos resíduos.

A RDC ANVISA 306/04, estabelece que deva haver um programa de educação continuada, visando à sensibilização, orientação e motivação de todos, alertando sobre os riscos e procedimentos adequados de manejo dos RSS. A única referencia que se tem é do treinamento da equipe de implantação do plano. A gestora do plano, em entrevista, relatou que são realizadas palestras a respeito do PGRSS com todos os envolvidos, porém não há registros que materialize esta atividade e posso registrar a frequência com que é realizada.

No plano não há menção de integração com outros planos, como é o caso do plano e resposta às emergências, plano de limpeza e manutenção do hospital.

Não há indicação dos períodos de dedetização ou imunização das áreas críticas do hospital.

A parte referente aos acidentes em serviço só descreve os acidentes com materiais perfuro cortantes e as medidas decorrentes, sendo uma oportunidade de melhorias descreverem outros tipos de acidentes possíveis, com os diversos tipos de 
RSS. Há que se considerar importante à elaboração de um plano de resposta à Emergência, para que se tenha normatizado todos os procedimentos a serem adotados em caso de acidente com qualquer tipo de RSS.

No PGRSS não está descrito a sua integração com o plano de limpeza diária do hospital, nem com as atividades desenvolvidas com a Comissão de Controle de Infecção Hospitalar, que é fundamental para que se tenham bons resultados neste processo.

No apêndice ao plano são previstas várias ações em relação os riscos potenciais, entretanto não se estabelece quem realiza, nem como, onde e com que frequência às ações será realizada.

\subsubsection{Tipos de Resíduos Gerados}

Conforme verificado, os seguintes tipos de resíduos são gerados no Hospital Militar de Área de Brasília:

\begin{tabular}{|c|c|c|c|}
\hline GRUPO & TIPO DE RESÍDUO & $\begin{array}{l}\text { LOCAL DE PRODU- } \\
\text { ÇÃO }\end{array}$ & ACONDICIONAMENTO \\
\hline \multirow[t]{3}{*}{ A1 } & $\begin{array}{l}\text { Culturas e estoques de } \\
\text { microorganismos; resí- } \\
\text { duos de fabricação de } \\
\text { produtos biológicos, exce- } \\
\text { to os hemoderivados; } \\
\text { descarte de vacinas de } \\
\text { microorganismos vivos ou } \\
\text { atenuados; meios de cul- } \\
\text { tura e instrumentais utili- } \\
\text { zados para transferência, } \\
\text { inoculação ou mistura de } \\
\text { culturas; resíduos de labo- } \\
\text { ratórios de manipulação } \\
\text { genética. }\end{array}$ & $\begin{array}{c}\text { LAC } \\
\text { Sala de Vacinas }\end{array}$ & \multirow[t]{3}{*}{$\begin{array}{l}\text { SACO PLÁSTICO VER- } \\
\text { MELHO,LEITOSO (deve- } \\
\text { rá ser tratado fora da uni- } \\
\text { dade, dentro de um sis- } \\
\text { tema único da Secretaria } \\
\text { de Estado) }\end{array}$} \\
\hline & $\begin{array}{l}\text { Bolsas transfusionais con- } \\
\text { tendo sangue ou hemo- } \\
\text { componentes rejeitadas } \\
\text { por contaminação ou por } \\
\text { má conservação, ou com } \\
\text { prazo de validade vencido, } \\
\text { e aquelas oriundas de } \\
\text { coleta incompleta. }\end{array}$ & $\begin{array}{l}\text { UCI } \\
\text { UIH }\end{array}$ & \\
\hline & $\begin{array}{l}\text { Sobras de amostras de } \\
\text { laboratório contendo san- } \\
\text { gue ou líquidos corpóreos, }\end{array}$ & $\begin{array}{c}\text { Ambulatório de Gine- } \\
\text { cologia } \\
\text { Anatomia Patológica }\end{array}$ & \\
\hline
\end{tabular}




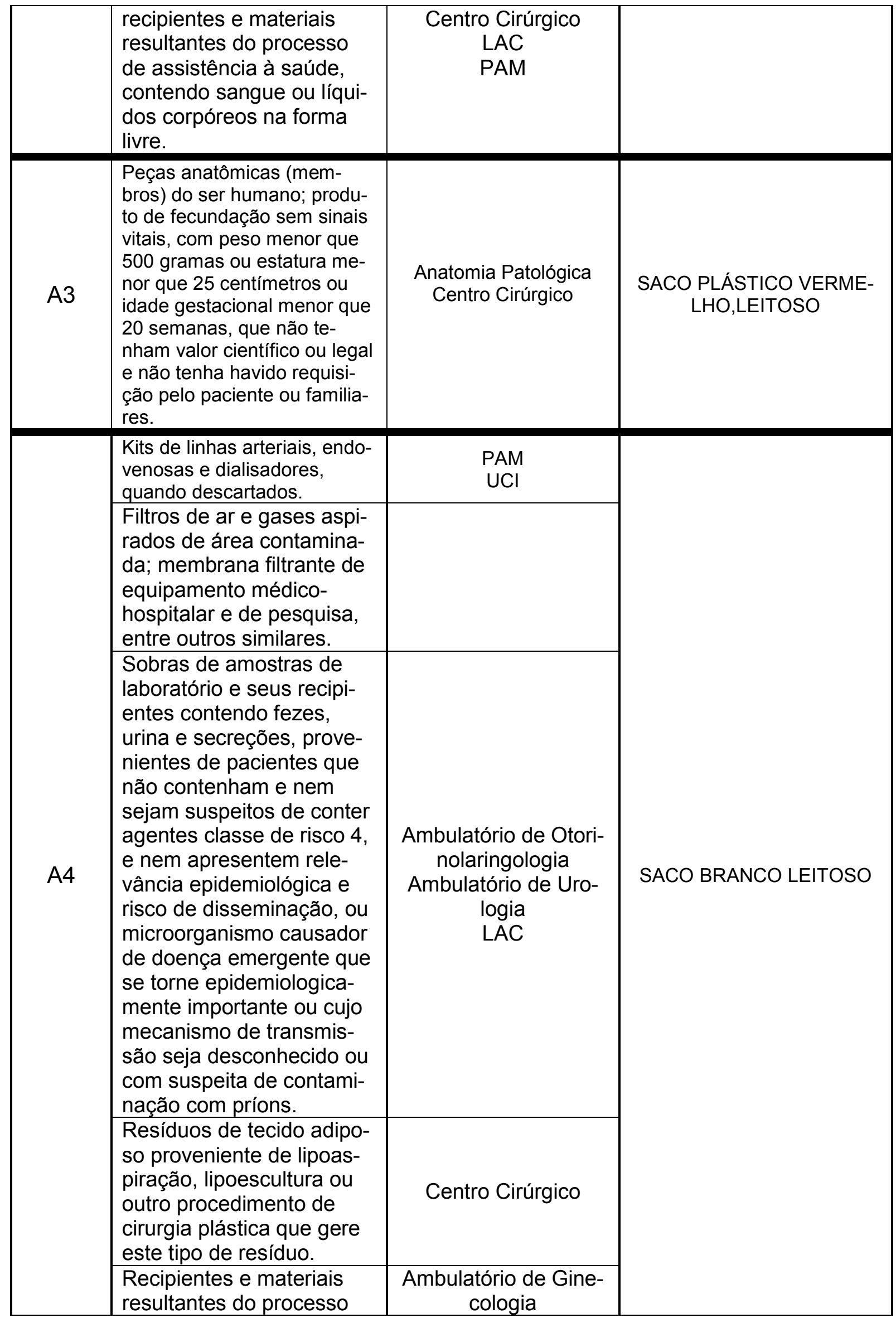




\begin{tabular}{|c|c|c|c|}
\hline & $\begin{array}{l}\text { de assistência à saúde, } \\
\text { que não contenham san- } \\
\text { gue ou líquidos corpóreos } \\
\text { na forma livre. }\end{array}$ & $\begin{array}{c}\text { Ambulatório de Uro- } \\
\text { logia } \\
\text { Centro Cirúrgico } \\
\text { LAC } \\
\text { Odontoclínica } \\
\text { Oncologia } \\
\text { PAD } \\
\text { PAM } \\
\end{array}$ & \\
\hline & $\begin{array}{l}\text { Peças anatômicas (órgãos } \\
\text { e tecidos) e outros resí- } \\
\text { duos provenientes de pro- } \\
\text { cedimentos cirúrgicos ou } \\
\text { de estudos anátomo- } \\
\text { patológicos ou de confir- } \\
\text { mação diagnóstica. }\end{array}$ & $\begin{array}{c}\text { Anatomia Patológica } \\
\text { Centro Cirúrgico } \\
\text { LAC } \\
\text { Odontoclínica }\end{array}$ & \\
\hline & $\begin{array}{l}\text { Bolsas transfusionais va- } \\
\text { zias ou com volume resi- } \\
\text { dual pós-transfusão (fo- } \\
\text { ram usadas) }\end{array}$ & $\begin{array}{c}\text { Centro Cirúrgico } \\
\text { UCI } \\
\text { UIH }\end{array}$ & \\
\hline \multirow{5}{*}{ B } & $\begin{array}{l}\text { Produtos hormonais e produ- } \\
\text { tos antimicrobianos; citostáti- } \\
\text { cos; antineoplásicos; } \\
\text { imunossupressores; digitáli- } \\
\text { cos; imunomoduladores; anti- } \\
\text { retrovirais, quando descarta- } \\
\text { dos por serviços de saúde, } \\
\text { farmácias, drogarias e distri- } \\
\text { buidores de medicamentos } \\
\text { ou apreendidos e os resí- } \\
\text { duos e insumos farmacêuti- } \\
\text { cos dos medicamentos con- } \\
\text { trolados pela Portaria MS } \\
344 / 98 \text { e suas atualizações. }\end{array}$ & $\begin{array}{c}\text { Ambulatório de Urologia } \\
\text { FAEx } \\
\text { Farmácia Hospitalar } \\
\text { Oncologia } \\
\text { PAM } \\
\text { UCI } \\
\text { UIH }\end{array}$ & \multirow{5}{*}{$\begin{array}{l}\text { - Substância perigosas (cor- } \\
\text { rosivas, reativas, tóxicas, } \\
\text { explosivas e inflamáveis): } \\
\text { conforme recomendações do } \\
\text { fabricante para acondicioná- } \\
\text { los e descartá-los. } \\
\text { - Resíduos sólidos: recipien- } \\
\text { tes rígidos, adequados para } \\
\text { cada tipo de substância quí- } \\
\text { mica, respeitadas as suas } \\
\text { características físico- } \\
\text { químicas e seu estado físico, } \\
\text { identificados de acordo com } \\
\text { suas especificações. } \\
\text { - Resíduos para reciclagem } \\
\text { ou reaproveitamento: em } \\
\text { recipientes individualizados: } \\
\text { *em recipientes rígidos, } \\
\text { sempre observando a com- } \\
\text { patibilidade química dos } \\
\text { componentes entre si, como } \\
\text { de cada resíduo com os } \\
\text { materiais da embalagem, } \\
\text { evitando reação química, } \\
\text { enfraquecimento ou deterio- } \\
\text { ração da embalagem, ou a } \\
\text { permeabilidade aos compo- } \\
\text { nentes do resíduo; identifi- } \\
\text { cados conforme lei. } \\
\text { *Embalagens primárias, se- } \\
\text { cundárias e os materiais } \\
\text { contaminados por substância } \\
\text { química - mesmo tratamento } \\
\text { das substâncias químicas } \\
\text { que as contaminaram. } \\
\text { *Embalagens secundárias, } \\
\text { que não entraram em conta- }\end{array}$} \\
\hline & $\begin{array}{l}\text { Resíduos de saneantes, } \\
\text { desinfetantes, desinfestan- } \\
\text { tes; resíduos contendo me- } \\
\text { tais pesados; reagentes para } \\
\text { laboratório, inclusive os reci- } \\
\text { pientes contaminados por } \\
\text { estes }\end{array}$ & $\begin{array}{c}\text { Ambulatório de Gineco- } \\
\text { logia } \\
\text { Ambulatório de Urologia } \\
\text { Anatomia Patológica } \\
\text { LAC }\end{array}$ & \\
\hline & $\begin{array}{l}\text { - Efluentes de processado- } \\
\text { res de imagem (reveladores } \\
\text { e fixadores). }\end{array}$ & $\begin{array}{c}\text { Odontoclínica } \\
\text { Radiologia e Diagnósti- } \\
\text { co por Imagem }\end{array}$ & \\
\hline & $\begin{array}{l}\text { Efluentes dos equipamentos } \\
\text { automatizados utilizados em } \\
\text { análises clínicas }\end{array}$ & LAC & \\
\hline & $\begin{array}{l}\text { Demais produtos considera- } \\
\text { dos perigosos, conforme } \\
\text { classificação da NBR } 10004 \\
\text { da } \\
\text { ABNT (tóxicos, corrosivos, } \\
\text { inflamáveis e reativos). }\end{array}$ & $\begin{array}{l}\text { Farmácia Hospitalar } \\
\text { LAC }\end{array}$ & \\
\hline
\end{tabular}




\begin{tabular}{|c|c|c|c|}
\hline & & & $\begin{array}{l}\text { to com o produto - fisica- } \\
\text { mente descaracterizadas e } \\
\text { acondicionadas como resí- } \\
\text { duo do grupo D. } \\
{ }^{*} \text { Resíduos com mercúrio } \\
\frac{(\mathrm{Hg}): \text { em recipientes sob selo }}{\text { d'água e encaminhados para }} \\
\text { recuperação. } \\
\text { *Disquetes: reciclar o plásti- } \\
\text { co e o metal } \\
\text { *Cartuchos de impressão: } \\
\text { recarga, caso não haja pos- } \\
\text { sibilidade de recarga => } \\
\text { resíduo resíduo do grupo D. } \\
\text { *Lâmpadas fluorescentes: } \\
\text { separadas do restante dos } \\
\text { resíduos para serem envia- } \\
\text { das à reciclagem. }\end{array}$ \\
\hline D & $\begin{array}{l}\text { - Papel de uso sanitário e } \\
\text { fralda, absorventes higiêni- } \\
\text { cos, peças descartáveis de } \\
\text { vestuário, } \\
\text { resto alimentar de pacientes, } \\
\text { material utilizado em anti- } \\
\text { sepsia e hemostasia de ve- } \\
\text { nóclises, } \\
\text { equipamento de soro e ou- } \\
\text { tros similares não classifica- } \\
\text { dos como A1. } \\
\text { - Sobras de alimentos e do } \\
\text { preparo de alimentos. } \\
\text { - Resto alimentar de refeitó- } \\
\text { rio. } \\
\text { - Resíduos provenientes das } \\
\text { áreas administrativas. } \\
\text { - Resíduos de varrição, flo- } \\
\text { res, podas e jardins. } \\
\text { - Resíduos de gesso prove- } \\
\text { nientes de assistência à saú- } \\
\text { de. }\end{array}$ & $\begin{array}{c}\text { Ambulatórios } \\
\text { Anatomia Patológica } \\
\text { Centro Cirúrgico } \\
\text { FAEx } \\
\text { Farmácia Hospitalar } \\
\text { Fisioterapia } \\
\text { LAC } \\
\text { Lavanderia } \\
\text { Odontoclínica } \\
\text { Oncologia } \\
\text { PAD } \\
\text { PAM } \\
\text { Radiologia e Diagnósti- } \\
\text { co por Imagem } \\
\text { Sala de Gesso } \\
\text { Sala de Vacinas } \\
\text { Setores Administrativos } \\
\text { do HMAB } \\
\text { UCl } \\
\text { UIH }\end{array}$ & $\begin{array}{l}\text { SACOS PLÁSTICOS PRE- } \\
\text { TOS, IMPERMEÁVEIS. }\end{array}$ \\
\hline$E$ & $\begin{array}{l}\text { Materiais perfurocortantes ou } \\
\text { escarificantes, tais como: } \\
\text { lâminas de barbear, agulhas, } \\
\text { escalpes, ampolas de vidro, } \\
\text { brocas, limas endodônticas, } \\
\text { pontas diamantadas, lâminas } \\
\text { de } \\
\text { bisturi, lancetas; tubos capi- } \\
\text { lares; micropipetas; lâminas } \\
\text { e lamínulas; espátulas; e } \\
\text { todos os } \\
\text { utensílios de vidro quebrados } \\
\text { no laboratório (pipetas, tubos } \\
\text { de coleta sanguínea e placas } \\
\text { de Petri) e outros similares }\end{array}$ & $\begin{array}{c}\text { Ambulatório de Cardio- } \\
\text { logia } \\
\text { Ambulatório de Gineco- } \\
\text { logia } \\
\text { Ambulatório de Otorino- } \\
\text { laringologia } \\
\text { Ambulatório de Urologia } \\
\text { Anatomia Patológica } \\
\text { Centro Cirúrgico } \\
\text { Farmácia Hospitalar } \\
\text { Fisioterapia } \\
\text { LAC } \\
\text { Lavanderia } \\
\text { Odontoclínica } \\
\text { Oncologia } \\
\text { PAD } \\
\text { PAM } \\
\text { Radiologia e Diagnósti- }\end{array}$ & $\begin{array}{l}\text { Recipiente rígido, estanque, } \\
\text { resistente à punctura, ruptu- } \\
\text { ra e vazamento, impermeá- } \\
\text { vel, com tampa, contendo a } \\
\text { simbologia da substância }\end{array}$ \\
\hline
\end{tabular}


Quadro 2- Tipos de Resíduos Gerados no HMAB.

Fonte: HMAB, 2012.

\subsubsection{Em Relação ao Manejo}

No plano de GRSS são apresentados os EPI, entretanto seria importante prevê treinamento visando o uso e a manutenção dos mesmos.

Outra melhoria seria a implantação de um cronograma de fiscalização, pelo gestor do PGRSS, com previsão de um relatório, visando minimizar os potenciais riscos durante o manejo dos resíduos.

Em consulta realizada com a gestora do PGRSS e por meio de visitações, verificou-se que este serviço é realizado por empresa terceirizada, juntamente com a limpeza diária do hospital, não podendo se atestar a capacitação de seus funcionários para o manejo de RSS,

O laboratório do hospital deposita RSS provenientes de restos de exame fezes e urina, diretamente na rede de esgoto. (HMAB, 2012).

\subsubsection{Em Relação à Segregação e ao Acondicionamento}

No item 6 do PGRSS do HMAB onde são indicados os tipos de RSS, com os respectivos locais de geração e forma de acondicionamento, seria interessante que constasse também o nome do responsável de cada setor, a fim de melhorar a comunicação e a fiscalização por parte do gestor do PGRSS.

Neste mesmo item, é relatado que são gerados resíduos do grupo $D$, provenientes das áreas administrativas do hospital, entretanto no quadro demonstrativo da quantidade de resíduos produzidos, não existe nenhuma anotação para os recicláveis, que com certeza existem, não sendo possível buscar a redução dos mesmos, pelo fato de não terem sido mensurados. (HMAB, 2012). 


\subsubsection{Em Relação ao Transporte Interno}

Nas orientações a respeito da coleta interna não estão definidas as rotas nem os horários desta atividade, dificultando o controle e a fiscalização, a fim de evitar que essa atividade seja realizada juntamente com a distribuição de alimentos, recolhimento de roupas ou nos horários mais movimentados do hospital, como exemplo o horário de visitas, como prevê a legislação vigente.

Não há indicação dos responsáveis pela coleta interna, não sendo possível fiscalizá-los, verificando se estão executando a atividade de forma correta e com o equipamento adequado.

No que tange a higienização dos veículos de coleta interna, não há registro de onde e de quem realiza esta tarefa. (HMAB, 2012).

\subsubsection{Em Relação ao Armazenamento Temporário e Externo}

No item que trata do armazenamento interno e externo, estas duas etapas são definidas no plano, entretanto o HMAB não possui área de armazenamento interno, depositando seus resíduos diretamente nos contêineres que se localizam na área de armazenamento externo, que não tem definido no plano a sua localização, para que todos os usuários tenham conhecimento. Não está regulamentado quem realiza e com qual frequência a higienização da área de depósito externa.

O local de armazenamento externo não está de acordo com as RDC 306/04 ANVISA, tendo locais que permitam a entrado de vetores, insetos e ratos, por não possuir tela. (HMAB, 2012).

\subsubsection{Em Relação ao Tratamento}

No item 7 do PGRSS do HMAB, no que tange à fase de tratamento dos resíduos, não são indicados os responsáveis, não há menção do local do manejo e nem se quem realiza esta tarefa está devidamente habilitado para tal.

Outro aspecto relevante é a indicação e a atribuição de responsabilidades divididas pelos turnos previstos no hospital, que são em número de três, manhã, tarde e noite, visto que o hospital trabalha desta forma, operando $24 \mathrm{~h}$ por dia e no pla- 
no em vigor não existe esta segmentação de responsabilidade pelos turnos. (HMAB, 2012).

\subsubsection{Em Relação à Coleta e Transporte Externo}

No item 7 do PGRSS do HMAB no que refere à coleta e ao transporte externo, o quadro de frequência não permite que se fiscalize com eficiência, a forma de carreta e a qualificação dos funcionários que a realiza, pois o mesmo não traz o dia e horários desta atividade, referindo-se apenas ao número de vezes que ocorre a coleta, semanalmente. No mesmo item, referindo-se ao tipo de veículo utilizado na coleta, não se pode atestar que o mesmo possui as características exigidas pelas nas normas vigentes, nem se a equipe de coleta possui equipamento e habilitação adequada necessária para realizar desinfecção de acidentes de pequenas proporções, possíveis de ocorrer durante esse procedimento. (HMAB, 2012).

\subsubsection{Em Relação à Disposição Final}

O Certificado de incineração que a empresa INCINERA entrega ao hospital, atestando a destinação final correta, não é fiscalizado, pois não há menção do local da destinação final dos resíduos, impossibilitando uma possível inspeção por parte do gestor do PGRSS, para averiguar se está de acordo com a resolução CONAMA N ${ }^{\circ} 237 / 97$. Esta medida visa proteger o gerador, pois por força da Resolução 358 CONAMA, o gerador é responsável por todas as etapas do gerenciamento de RSS, que vai desde a sua geração até a destinação final, sendo passível de sanções, solidariamente com a empresa terceirizada. (HMAB, 2012).

\section{PROPOSTA DE SOLUÇÃO DA SITUAÇÃO PROBLEMA}

\subsection{PROPOSTA DE MELHORIA PARA A REALIDADE ESTUDADA}

Após visitas feitas ao HMAB, entrevistas com servidores de diversos setores e uma análise do PGRSS observamos que o hospital deixa a desejar em alguns pontos na gestão de resíduos de saúde, fazendo surgir assim riscos potenciais à 
saúde das pessoas que orbitam em torno deste hospital e do meio ambiente no qual está inserido.

Os estudos realizados fez chegarmos a algumas propostas para minimizar possíveis problemas no futuro:

a) Retificação do PGRSS: O Plano de Gestão de Resíduos do Serviço de Saúde deve ser constantemente atualizado e retificado para que com isso siga as normas vigentes. Alguns pontos mostrados no item anterior que vai do manejo a disposição final dos resíduos possui faIhas em suas rotinas. Muito dessas falhas podem ser justificadas, pois os procedimentos que devem ser adotados não estão completamente especificados no plano.

b) Aumentar a fiscalização e o controle: Como responsável pelo PGRSS, o gestor mais a sua equipe tem como atribuição fiscalizar e controlar todas as rotinas realizadas pelos que estão diretamente e indiretamente envolvidos na gestão dos resíduos do serviço de saúde. No estudo verificamos um déficit nessa fiscalização e nesse controle. Para facilitar este procedimento orientamos a criação de novas planiIhas e melhoramento nas planilhas já existentes. Além disso, realizar a implantação de um cronograma de fiscalização, pelo gestor do PGRSS, com previsão de um relatório, visando minimizar os potenciais riscos durante o manejo dos resíduos. Tudo isso possibilitará a redução de gastos de materiais e a constante identificação de possíveis problemas futuros.

c) Criação de uma fase de recuperação de resíduos recicláveis: $A$ criação de uma fase de Recuperação (reciclagem e reutilização) dos resíduos sólidos é de extrema importância para a minimização da quantidade de resíduos e, por consequência, diminuição dos custos e dos riscos que os mesmos representam, uma vez que os resíduos recuperados vão ser manipulados de modo diferente, não sendo necessários tratamentos especiais (incineração, autoclavagem) e a disposição final. No caso de resíduos de serviços de saúde a recuperação só 
é possível através de uma segregação bem feita na origem, o que durante os estudos se mostrou bastante ineficiente.

d) Construção de uma área de armazenamento interno e adequação da área de armazenamento conforme previsto em legislação: $O$ hospital acabou de passar por uma reforma recente em todos os seus setores, buscando com isso melhorar o atendimento do público alvo. Mesmo assim durante as visitas realizadas constatamos que o mesmo não possui uma área de armazenamento interno dos resíduos. A justificativa dada pelo gestor é que devido à estrutura do hospital ser bastante antiga e a legislação vigente ser recente, o HMAB não possui uma área para dispor para o procedimento de armazenamento interno. Já a área de armazenamento externo precisa ser reformada. Foi verificado pontos por onde animais vetores de doenças possuem acesso.

e) Realização de cursos e palestras de capacitação do pessoal envolvido em todo o processo de gestão dos resíduos de serviço de saúde, inclusive funcionários da empresa INCINERA: Apesar de ser especificada no PGRSS, a realização de palestras para toda a equipe envolvida na gestão dos resíduos do hospital, verificamos através de entrevistas que uma parte da equipe desconhece alguns procedimentos para a realização do manuseio. Não foi dito pelo gestor qual é a frequência da realização dessas palestras. No PGRSS é especificada a realização de curso de capacitação de alguns integrantes da equipe realizado no ano de 2010 , mas em nenhum momento é taxativo quando se refere quem realizou esse curso.

f) Cobrar adequação das normas vigentes por parte da empresa INCINERA: A empresa responsável pela destinação final dos resíduos não especifica o lugar que é feito este procedimento. Além disso, foi constatado problemas no manuseio por parte dos funcionários da empresa e no tipo de veículo utilizado para o transporte. Com isso deve haver uma maior cobrança por parte do HMAB para que a empresa 
tome os procedimentos corretos. Caso isso não seja feito a empresa INCINERA está violando uma das cláusulas do contrato feito através de licitação, podendo o mesmo ser reincidido.

\subsection{RESULTADOS ESPERADOS}

A partir das propostas de melhorias espera-se extinguir ou pelo menos amenizar os elementos que atingem consideravelmente todos os procedimentos realizados para a gestão dos resíduos de saúde desta Unidade Hospitalar do Exército Brasileiro, almejando uma melhora constante em todos os processos observados.

Apesar de existir um problema conjuntural na estrutura do Exército o que ocasiona em uma lentidão para que rotinas e procedimentos sejam adotados, tudo que foi sugerido por este estudo ao gestor do PGRSS do hospital visa alcançar a excelência na gestão gerencial, que irá levar as observações feitas neste estudo ao diretor do hospital e solicitar também prioridade em alguns pontos que apresentaram certa deficiência.

\subsection{VIABILIDADE DA PROPOSTA}

A implantação de novas rotinas e a retificação de outras já existentes mostra que a proposta sugerida por este esse estudo é cem por cento, viável, já que praticamente não ocorrerá o aumento de gastos por parte da administração do hospital. O que foi constatado realmente é a impossibilidade de se construir uma área de armazenamento interno devido à estrutura antiga do hospital, faltando um espaço adequado para a realização dessa obra. Já a adequação da área de armazenamento externo, mais a contratação da alguns cursos de capacitação, apresentam um ótimo custo benefício.

\section{CONSIDERAÇÕES FINAIS}

Na concepção da nova ordem mundial de proteção ao meio ambiente e à vida, há que se ter a sensibilidade de entender a importância da existência de medidas para a gestão de resíduos sólidos, por parte de toda a sociedade, e principal- 
mente, dos geradores de resíduos de serviço de saúde, com o objetivo de melhorar a qualidade de vida e de preservação do meio ambiente, das atuais e futuras gerações.

Os desafios e as possibilidades para alcançar estes objetivos estão presentes em todas as ações e buscam alternativas éticas e ecologicamente corretas para responder às demandas impostas pela evolução tecnológica.

A partir da globalização e da velocidade dos acontecimentos, a sociedade da informação e do conhecimento, assim denominada na atualidade, carrega uma multiplicidade de fatores que não permitem em nenhum momento certezas absolutas ou verdades incontestáveis. As constantes mudanças e seus contingentes carregam consigo um cabedal de incertezas e, por mais que se façam pesquisas e se comprovem teorias, estas serão sempre relativas e submetidas a um determinado tempo histórico-social. Dessa constatação emerge a incompletude do ser humano, e consequentemente, do ser social, que é fator primordial para a preservação ambiental.

A Legislação Brasileira e seus órgãos reguladores estabelecem normas para o gerenciamento dos resíduos de serviços de saúde, entretanto há que haver uma conscientização para o correto cumprimento destas normas. O gerenciamento correto dos resíduos de saúde é fundamental para a concretização dos objetivos propostos.

Após analisar as normas e publicações atinentes à gestão de resíduos de saúde e de preservação do meio ambiente, abordando os aspectos relacionados ao gerenciamento de resíduos, as medidas que podem ser tomadas para minimizar a geração desses resíduos, discorrendo sobre o papel de profissionais na geração dos mesmos, além da preocupação de estabelecimentos de saúde em elaborar e executar o PGRSS e do cumprimento de leis por parte de autoridades sanitárias e de meio ambiente, pode-se concluir que a gestão de resíduos de saúde é fundamental para a melhoria da qualidade de vida da sociedade e para a preservação do meio ambiente, proporcionando ao país oportunidades de crescimento sustentável.

A realização deste trabalho teve como finalidade analisar o PGRSS do HMAB e propor ações de inovação e melhoria neste, com fulcro na minimização da produção de resíduos, bem como proporcionar um encaminhamento seguro dos resíduos gerados. Para que este objetivo seja alcançado, propostas simples de custo quase irrisório, foram levantadas. 
Por fim, caso as adequações necessárias das rotinas realizadas pelo o HMAB no gerenciamento e gestão de resíduos do serviço de saúde, sejam realizadas conforme propostas por este estudo, o mesmo alcançará o nível de excelência gerencial tão almejado pelo Exército Brasileiro, servindo como referência não somente para todas as unidades de saúde da força, mas também para todas as organizações militares e suas diversas especializações. Com isso todos serão protagonistas na preservação ambiental. Já no caso do HMAB por ser um gerador de RSS, minimizará os riscos potenciais à saúde das pessoas que orbitam em torno deste hospital e do meio ambiente no qual ele está inserido.

\title{
WASTE MANAGEMENT OF MILITARY HOSPITAL AREA OF BRASILIA
}

\begin{abstract}
The Management of Remainders of Health Service (MRHS) can be considered a complex process of transformation, as much the effective management of these remainders in all parts of this process, by all the professionals direct connected with it, as in the organizational culture that is indispensable for its efficiency. The establishment of a Management Plan of Remainders of Health Service in a hospital is fundamental to minimize the potential risks to the population's health and to the environment. This present resume (work) was written to analyze the MRHS established in the Military Hospital of Brasilia's Area, in search to describe its structure and the kind of services provided to the military family of Brasilia's Garrison, aiming of propose of innovations and improvements in the same, in order to permit the management upgrading of the remainders produced in this hospital, contributing like this for the improvement of population's health and for the environmental preservation.
\end{abstract}

Keywords: Solid Remainders, Remainders of Health Service and Management Plan of Remainders 


\section{REFERÊNCIAS}

ANVISA. Resolução RDC 306, de 7 de dezembro de 2004. Dispõe sobre o Regulamento Técnico para o gerenciamento de resíduos de serviços de saúde, da Agencia Nacional de Vigilância Sanitária.

ANVISA - Agência Nacional de Vigilância Sanitária. Resolução RDC 50, de 21 de fevereiro de 2002 - Dispõe sobre o Regulamento Técnico para planejamento, programação, elaboração e avaliação de projetos físicos de estabelecimentos assistenciais de saúde.

ASSOCIAÇÃO BRASILEIRA DE NORMAS TÉCNICAS. NBR 7500 - Símbolos de Risco e Manuseio para o Transporte e Armazenamento de Material, de março de 2000.

ASSOCIAÇÃO BRASILEIRA DE NORMAS TÉCNICAS. NBR 10004 - Resíduos Sólidos - Classificação, segunda edição - 31 de maio de 2004.

ASSOCIAÇÃO BRASILEIRA DE NORMAS TÉCNICAS. NBR 14652 - Coletortransportador rodoviário de resíduos de serviços de saúde, de abril de 2001.

BRASIL. Constituição (1988). Constituição da República Federativa da Brasil. Brasília, DF: senado, 1988.

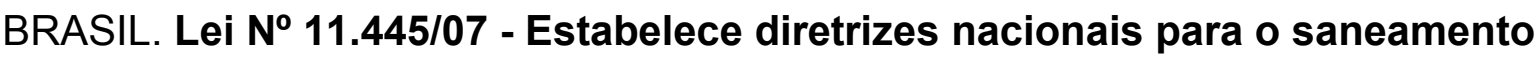
básico. Disponível em < www.planalto.gov.br >. Acessado em: 05 Set. 2012.

BRASIL. Lei N 12.305/10 - Institui a Política Nacional de Resíduos Sólidos. Disponível em < www.planalto.gov.br >. Acessado em: 05 Set. 2012.

CNEN, Norma NE 6.05, Gerência de Rejeitos Radioativos em Instalações Radiativas, do Conselho Nacional de Energia Nuclear. 
CONAMA - Conselho Nacional do Meio Ambiente. Resolução n 6, de 19 de setembro de 1991 - Dispõe sobre a incineração de resíduos sólidos provenientes de estabelecimentos de saúde, portos e aeroportos.

CONAMA - Conselho Nacional do Meio Ambiente. Resolução $\mathbf{n}^{\circ} \mathbf{5}$, de 05 de agosto de 1993 - Estabelecem definições, classificação Séries Temáticas ANVISA Tecnologias em Serviços de Saúde Volume 1 e procedimentos mínimos para o gerenciamento de resíduos sólidos oriundos de serviços de saúde, portos e aeroportos, terminais ferroviários e rodoviários.

CONAMA - Conselho Nacional do Meio Ambiente. Resolução n 237, de 22 de dezembro de 1997 - Regulamenta os aspectos de licenciamento ambiental estabelecidos na Política Nacional do Meio Ambiente.

CONAMA - Conselho Nacional do Meio Ambiente. Resolução nº 283, de 12 de julho de 2001 - "Dispõe sobre o tratamento e a destinação final dos resíduos dos serviços de saúde, tratamento ou disposição final ambientalmente adequado".

CONAMA, Resolução n 358, de 29 de abril de 2005.

Gerenciamento dos Resíduos de Serviço de Saúde, ANVISA, Brasília, 2006.

OPAS. Guia para manejo interno de resíduos sólidos em estabelecimento de saúde, da Organização Pan-Americana da Saúde, Brasília, 1997. 


\section{ANEXO - A}

MINISTÉRIO DA DEFESA

EXÉRCITO

BRASILEIRO

CMP $-11^{\text {a }}$ REGIÃO MILITAR

HOSPITAL MILITAR DE ÁREA DE BRASÍLIA

\section{Plano de Gerenciamento de Resíduos do Serviço de Saúde - HMAB}

\section{1 - Dados Gerais do Estabelecimento}

\begin{tabular}{|l|l|}
\hline Razão social & Hospital Militar de área de Brasília \\
\hline Nome fantasia & HMAB \\
\hline Tipo de estabelecimento & Hospitalar \\
\hline Propriedade & Exército Brasileiro \\
\hline CNPJ & $09553484 / 0002$ - 51 \\
\hline Endereço & Setor Militar Urbano \\
\hline Bairro & Setor Militar Urbano \\
\hline Município & Brasília \\
\hline Estado & D.F. \\
\hline Fone(s) & 33626300 \\
\hline Fax & 33626317 \\
\hline Site & www.hmab.eb.mil.br \\
\hline E-mail & hgb-sec@eb.mil.br \\
\hline Horários de funcionamento & 24 horas por dia / 7 dias por semana \\
\hline Responsável legal & Cel Med Paulo Sérgio Iglessias \\
\hline Data de fundação & 29 de junho de 1965 \\
\hline
\end{tabular}


2- Componentes da Equipe de Elaboração

\begin{tabular}{|l|l|}
\hline Responsável pelo PGRSS & $\begin{array}{l}\text { Maj QCO Kenia Gomes do Carmo Pi- } \\
\text { canço }\end{array}$ \\
\hline Identificação ART do responsável & \\
\hline Número do conselho de classe & COREN-DF 38252 \\
\hline Nome dos técnicos / cargos & Cap Dent Lícia Flores Basto Carvalhães \\
\cline { 2 - 2 } & Cap R2 José Carlos AMARAL Alves \\
\cline { 2 - 2 } & $1^{\circ}$ Ten Thaís Helena Madureira \\
\cline { 2 - 2 } & $1^{\circ}$ Ten Lara Crisrina Ferreira Malheiros \\
\cline { 2 - 2 } & $2^{\circ}$ Ten Leyg Meire Barbosa Caixeta \\
\cline { 2 - 2 } & $2^{\circ}$ Sgt Inf Juliandrey Oliveira Moreira \\
\hline Nome da empresa contratada & Incinera Tratamento de Resíduos Ltda \\
\hline Identificação ART da empresa & \\
\hline Número do conselho de classe & \\
\hline
\end{tabular}

\section{3 - Caracterização do Estabelecimento}

\begin{tabular}{|c|c|}
\hline \multirow[t]{3}{*}{ Número total de servidores } & Militares 575 \\
\hline & Civis \\
\hline & Total \\
\hline $\begin{array}{l}\text { Condição de funcionamento do estabele- } \\
\text { cimento }\end{array}$ & Em atividade \\
\hline \multirow[t]{4}{*}{ Tipo de serviços terceirizados } & Manutenção ( ) \\
\hline & Limpeza (X) \\
\hline & Serviços clínicos ( ) \\
\hline & Outros (X) \\
\hline $\begin{array}{l}\text { Número total de funcionários de empresas } \\
\text { terceirizadas }\end{array}$ & Unilimps - 70 \\
\hline Área total construída & $8.540,9 \mathrm{~m}^{2}$ \\
\hline Área total do terreno & $18.304,3 \mathrm{~m}^{2}$ \\
\hline \multicolumn{2}{|l|}{ Alvará sanitário } \\
\hline Licença ambiental (qdo exigido) & XxXXXXXXX \\
\hline Horário de funcionamento & $\begin{array}{l}\text { 07:00 às } 22: 00 \text { horas (ambulatorial) } \\
\text { PAM } 24 \text { horas }\end{array}$ \\
\hline \multirow[t]{2}{*}{ Estrutura física } & Tipo de construção: alvenaria \\
\hline & Número de pavimentos: 01 \\
\hline \multirow[t]{3}{*}{ Abastecimento de água } & Concessionária: CAESB \\
\hline & Consumo interno: $3.331 \mathrm{~m}^{3} / \mathrm{mês}$ \\
\hline & Número de reservatórios: 01 \\
\hline \multirow[t]{3}{*}{ Condições urbanas do entorno } & Condições de acesso: terrestre \\
\hline & Risco de enchentes: não há \\
\hline & Risco de deslizamento: não há \\
\hline Coleta de esgoto sanitário & Coleta e tratamento público: total \\
\hline
\end{tabular}




\begin{tabular}{|l|l|}
\hline & Só coleta: sim \\
\cline { 2 - 2 } & Sem coleta: não \\
\cline { 2 - 2 } & Tratamento próprio: não \\
\hline
\end{tabular}

\section{4 - Organograma do Estabelecimento}

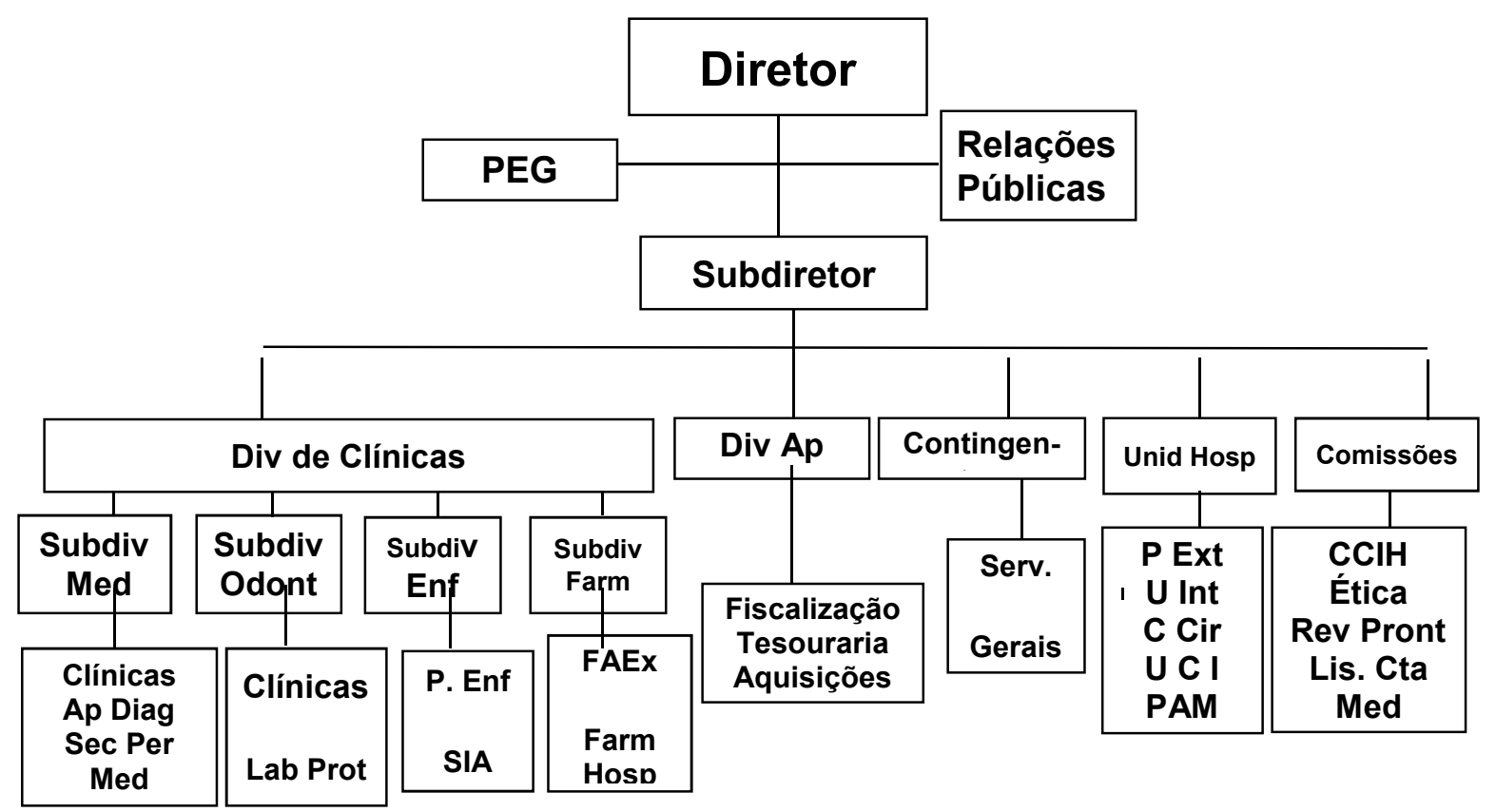

\section{5 - Caracterização das Atividades e Serviços do Estabelecimento}

\begin{tabular}{|c|c|}
\hline \multirow{13}{*}{$\begin{array}{c}\text { Tipos de especialidades médicas e/ou } \\
\text { assistenciais }\end{array}$} & Anatomia Patologica \\
\hline & Anestesiologia \\
\hline & Cardiologia \\
\hline & Cirurgia geral \\
\hline & Cirurgia plástica \\
\hline & Cirurgia vascular \\
\hline & Clínica geral \\
\hline & Dermatologia \\
\hline & Endocrinologia \\
\hline & Gastroenterologia \\
\hline & Geriatria \\
\hline & Gineco/obstetrícia \\
\hline & Hematologia \\
\hline
\end{tabular}




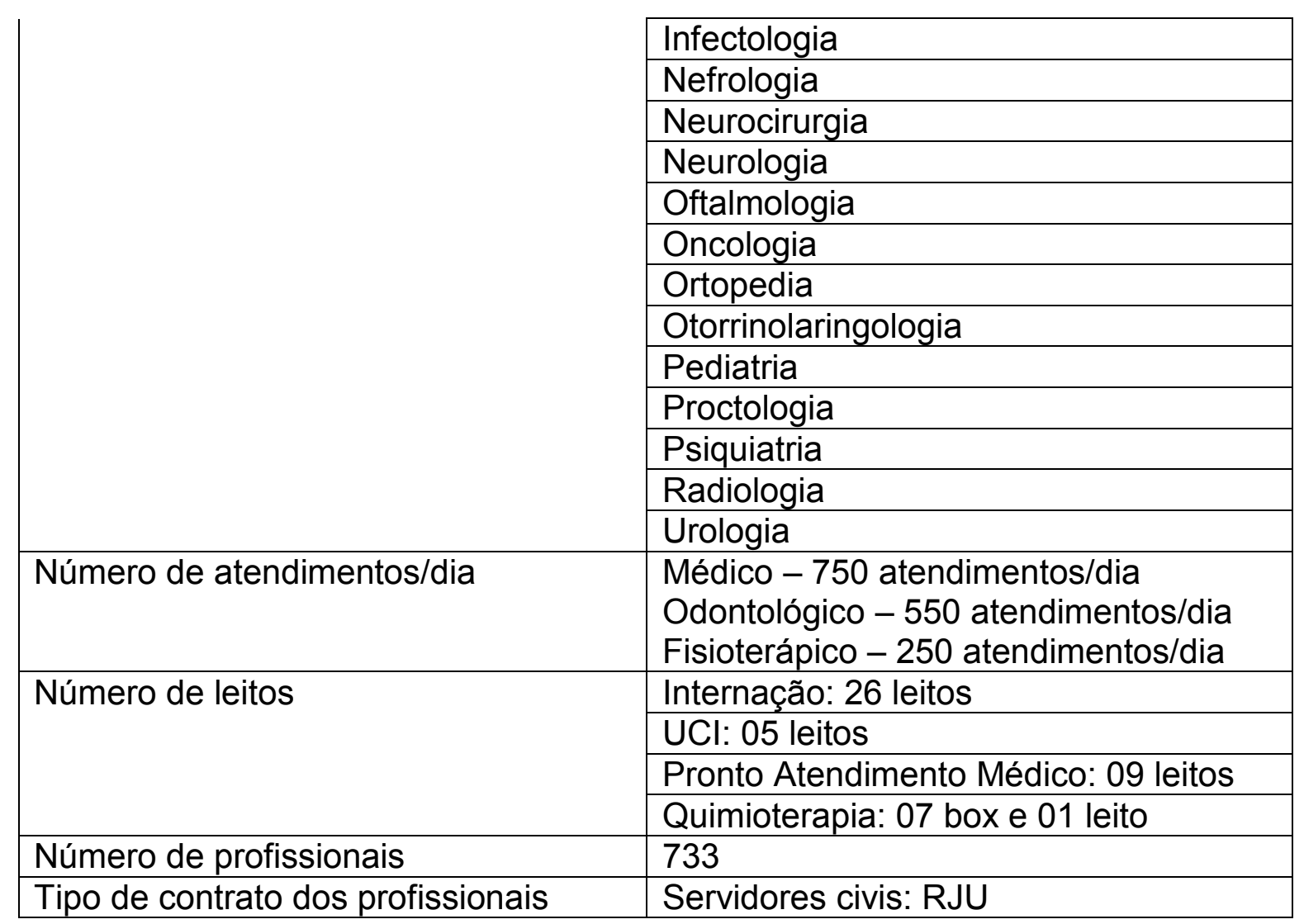

\section{6 - Tipos de Resíduos Gerados}

\begin{tabular}{|c|l|c|c|}
\hline GRUPO & \multicolumn{1}{|c|}{ TIPO DE RESÍDUO } & $\begin{array}{c}\text { LOCAL DE PRODU- } \\
\text { ÇÃO }\end{array}$ & ACONDICIONAMENTO \\
\hline & $\begin{array}{l}\text { Culturas e estoques de } \\
\text { microorganismos; resí- } \\
\text { duos de fabricação de } \\
\text { produtos biológicos, exce- } \\
\text { to os hemoderivados; } \\
\text { descarte de vacinas de } \\
\text { microorganismos vivos ou } \\
\text { atenuados; meios de cul- } \\
\text { tura e instrumentais utili- } \\
\text { zados para transferência, } \\
\text { inoculação ou mistura de } \\
\text { culturas; resíduos de labo- } \\
\text { ratórios de manipulação } \\
\text { genética. }\end{array}$ & Sala de Vacinas & LACO PLÁSTICO VER- \\
\cline { 2 - 4 } & $\begin{array}{l}\text { Bolsas transfusionais con- } \\
\text { tendo sangue ou hemo- } \\
\text { componentes rejeitadas } \\
\text { por contaminação ou por } \\
\text { má conservação, ou com } \\
\text { prazo de validade vencido, } \\
\text { e aquelas oriundas de } \\
\text { coleta incompleta. }\end{array}$ & $\begin{array}{c}\text { Sá ser tratado fora da uni- } \\
\text { dade, dentro de um sis- } \\
\text { tema único da Secretaria } \\
\text { de Estado) }\end{array}$ \\
\hline
\end{tabular}




\begin{tabular}{|c|c|c|c|}
\hline & $\begin{array}{l}\text { Sobras de amostras de } \\
\text { laboratório contendo san- } \\
\text { gue ou líquidos corpóreos, } \\
\text { recipientes e materiais } \\
\text { resultantes do processo } \\
\text { de assistência à saúde, } \\
\text { contendo sangue ou líqui- } \\
\text { dos corpóreos na forma } \\
\text { livre. }\end{array}$ & $\begin{array}{c}\text { Ambulatório de Gine- } \\
\text { cologia } \\
\text { Anatomia Patológica } \\
\text { Centro Cirúrgico } \\
\text { LAC } \\
\text { PAM }\end{array}$ & \\
\hline A3 & $\begin{array}{l}\text { Peças anatômicas (mem- } \\
\text { bros) do ser humano; produ- } \\
\text { to de fecundação sem sinais } \\
\text { vitais, com peso menor que } \\
500 \text { gramas ou estatura me- } \\
\text { nor que } 25 \text { centímetros ou } \\
\text { idade gestacional menor que } \\
20 \text { semanas, que não te- } \\
\text { nham valor científico ou legal } \\
\text { e não tenha havido requisi- } \\
\text { ção pelo paciente ou familia- } \\
\text { res. }\end{array}$ & $\begin{array}{l}\text { Anatomia Patológica } \\
\text { Centro Cirúrgico }\end{array}$ & $\begin{array}{c}\text { SACO PLÁSTICO VERME- } \\
\text { LHO,LEITOSO }\end{array}$ \\
\hline \multirow{5}{*}{ A4 } & $\begin{array}{l}\text { Kits de linhas arteriais, endo- } \\
\text { venosas e dialisadores, } \\
\text { quando descartados. }\end{array}$ & $\begin{array}{l}\text { PAM } \\
\text { UCl }\end{array}$ & \multirow{5}{*}{ SACO BRANCO LEITOSO } \\
\hline & $\begin{array}{l}\text { Filtros de ar e gases aspi- } \\
\text { rados de área contamina- } \\
\text { da; membrana filtrante de } \\
\text { equipamento médico- } \\
\text { hospitalar e de pesquisa, } \\
\text { entre outros similares. }\end{array}$ & & \\
\hline & $\begin{array}{l}\text { Sobras de amostras de } \\
\text { laboratório e seus recipi- } \\
\text { entes contendo fezes, } \\
\text { urina e secreções, prove- } \\
\text { nientes de pacientes que } \\
\text { não contenham e nem } \\
\text { sejam suspeitos de conter }\end{array}$ & & \\
\hline & $\begin{array}{l}\text { agentes classe de risco 4, } \\
\text { e nem apresentem rele- } \\
\text { vância epidemiológica e } \\
\text { risco de disseminação, ou } \\
\text { microorganismo causador } \\
\text { de doença emergente que } \\
\text { se torne epidemiologica- } \\
\text { mente importante ou cujo } \\
\text { mecanismo de transmis- } \\
\text { são seja desconhecido ou } \\
\text { com suspeita de contami- } \\
\text { nação com príons. }\end{array}$ & $\begin{array}{l}\text { Ambulatório de Otori- } \\
\text { nolaringologia } \\
\text { Ambulatório de Uro- } \\
\text { logia } \\
\text { LAC }\end{array}$ & \\
\hline & $\begin{array}{l}\text { Resíduos de tecido adipo- } \\
\text { so proveniente de lipoas- } \\
\text { piração, lipoescultura ou } \\
\text { outro procedimento de } \\
\text { cirurgia plástica que gere }\end{array}$ & Centro Cirúrgico & \\
\hline
\end{tabular}




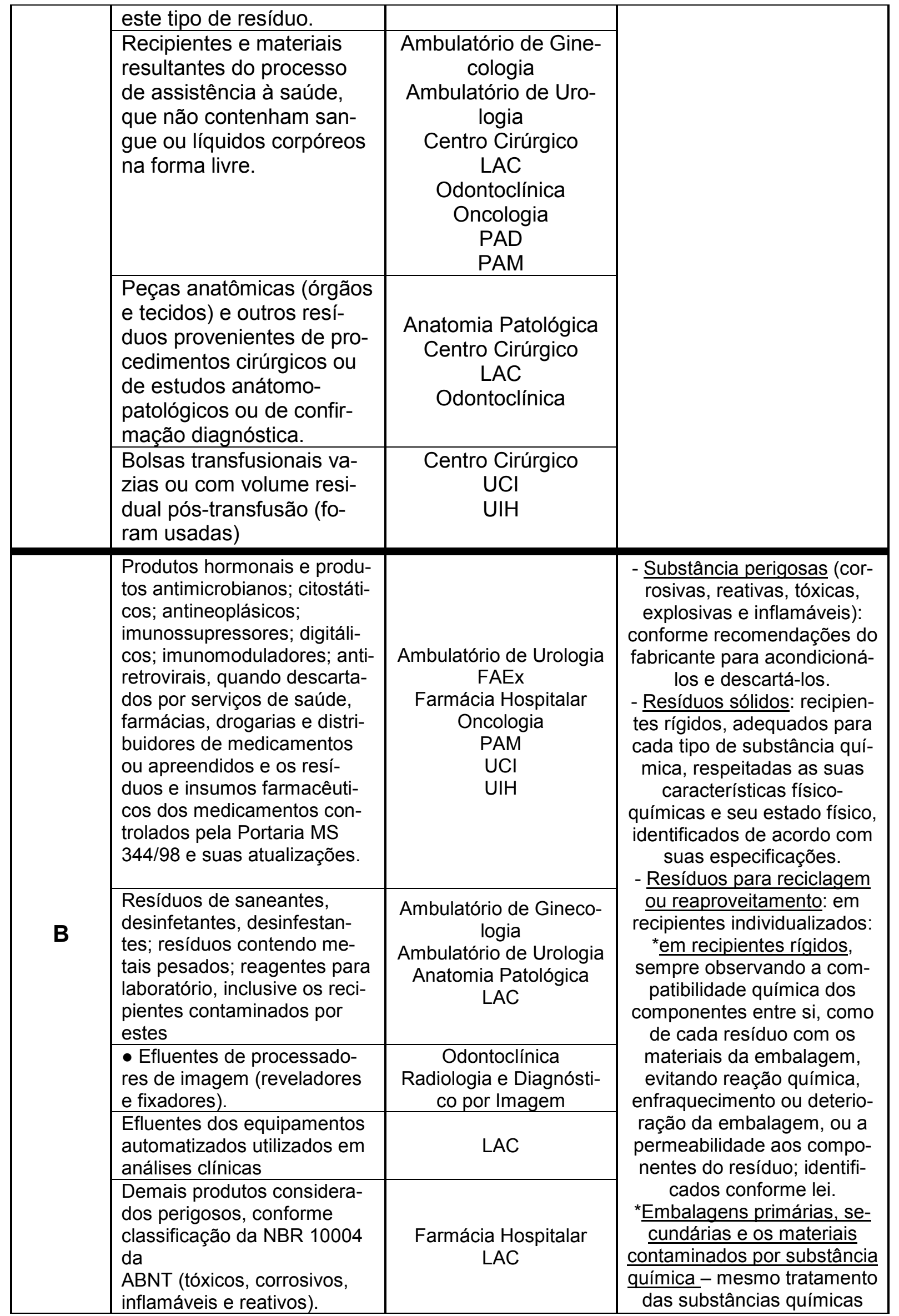




\begin{tabular}{|c|c|c|c|}
\hline & & & 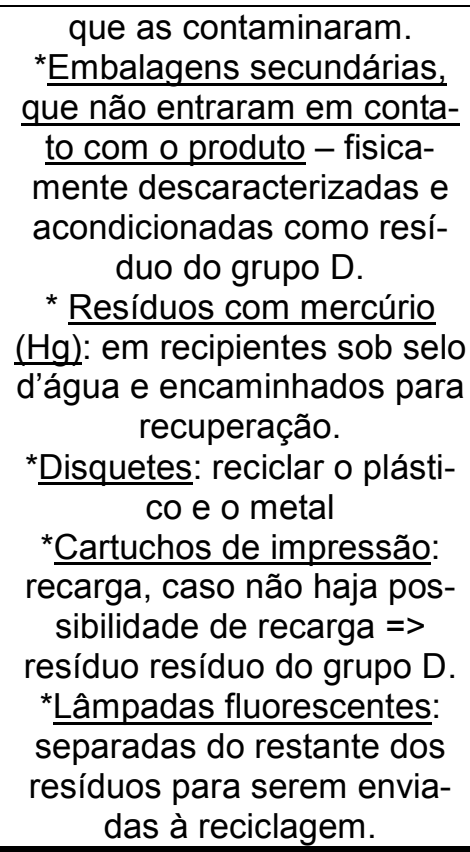 \\
\hline D & $\begin{array}{l}\text { - Papel de uso sanitário e } \\
\text { fralda, absorventes higiêni- } \\
\text { cos, peças descartáveis de } \\
\text { vestuário, } \\
\text { resto alimentar de pacientes, } \\
\text { material utilizado em anti- } \\
\text { sepsia e hemostasia de ve- } \\
\text { nóclises, } \\
\text { equipamento de soro e ou- } \\
\text { tros similares não classifica- } \\
\text { dos como A1. } \\
\text { - Sobras de alimentos e do } \\
\text { preparo de alimentos. } \\
\text { - Resto alimentar de refeitó- } \\
\text { rio. } \\
\text { - Resíduos provenientes das } \\
\text { áreas administrativas. } \\
\text { - Resíduos de varrição, flo- } \\
\text { res, podas e jardins. } \\
\text { - Resíduos de gesso prove- } \\
\text { nientes de assistência à saú- } \\
\text { de. }\end{array}$ & $\begin{array}{c}\text { Ambulatórios } \\
\text { Anatomia Patológica } \\
\text { Centro Cirúrgico } \\
\text { FAEx } \\
\text { Farmácia Hospitalar } \\
\text { Fisioterapia } \\
\text { LAC } \\
\text { Lavanderia } \\
\text { Odontoclínica } \\
\text { Oncologia } \\
\text { PAD } \\
\text { PAM } \\
\text { Radiologia e Diagnósti- } \\
\text { co por Imagem } \\
\text { Sala de Gesso } \\
\text { Sala de Vacinas } \\
\text { Setores Administrativos } \\
\text { do HMAB } \\
\text { UCl } \\
\text { UIH }\end{array}$ & $\begin{array}{l}\text { SACOS PLÁSTICOS PRE- } \\
\text { TOS, IMPERMEÁVEIS. }\end{array}$ \\
\hline$E$ & $\begin{array}{l}\text { Materiais perfurocortantes ou } \\
\text { escarificantes, tais como: } \\
\text { lâminas de barbear, agulhas, } \\
\text { escalpes, ampolas de vidro, } \\
\text { brocas, limas endodônticas, } \\
\text { pontas diamantadas, lâminas } \\
\text { de } \\
\text { bisturi, lancetas; tubos capi- } \\
\text { lares; micropipetas; lâminas } \\
\text { e lamínulas; espátulas; e } \\
\text { todos os } \\
\text { utensílios de vidro quebrados } \\
\text { no laboratório (pipetas, tubos } \\
\text { de coleta sanguínea e placas } \\
\text { de Petri) e outros similares }\end{array}$ & $\begin{array}{c}\text { Ambulatório de Cardio- } \\
\text { logia } \\
\text { Ambulatório de Gineco- } \\
\text { logia } \\
\text { Ambulatório de Otorino- } \\
\text { laringologia } \\
\text { Ambulatório de Urologia } \\
\text { Anatomia Patológica } \\
\text { Centro Cirúrgico } \\
\text { Farmácia Hospitalar } \\
\text { Fisioterapia } \\
\text { LAC } \\
\text { Lavanderia } \\
\text { Odontoclínica } \\
\text { Oncologia }\end{array}$ & $\begin{array}{l}\text { Recipiente rígido, estanque, } \\
\text { resistente à punctura, ruptu- } \\
\text { ra e vazamento, impermeá- } \\
\text { vel, com tampa, contendo a } \\
\text { simbologia da substância }\end{array}$ \\
\hline
\end{tabular}




\section{PAD}

PAM

Radiologia e Diagnósti-

co por Imagem

Sala de Vacinas

$\mathrm{UCl}$

$\mathrm{UIH}$

$A=$ resíduos do grupo $A$.

$B=$ resíduos do grupo $B$.

$\mathrm{C}=$ rejeitos do grupo $\mathrm{C}$.

$\mathrm{D}=$ resíduos do grupo $\mathrm{D}$.

$\mathrm{E}=$ resíduos perfurocortantes.

$\mathrm{RE}=$ resíduos recicláveis (papelão, vidro, metais, outros).

$E S$ = resíduos específicos (entulhos, móveis, eletroeletrônicos, lâmpadas fluorescentes etc.).

\section{Quantidade de resíduos coletados por grupo de resíduos}

\begin{tabular}{|l|c|c|c|c|c|c|c|c|c|c|c|c|}
\hline \multicolumn{1}{|c|}{ Grupos } & jan & fev & $\begin{array}{c}\text { ma } \\
r\end{array}$ & abr & mai & jun & jul & ago & set & out & nov & $\begin{array}{c}\text { De } \\
\text { z }\end{array}$ \\
\hline A & & & & & & & & & & & & \\
\hline B & & & & & & & & & & & & \\
\hline C & & & & & & & & & & & & \\
\hline E & & & & & & & & & & & & \\
\hline TOTAL & $\begin{array}{c}203, \\
6\end{array}$ & $\begin{array}{c}224, \\
5\end{array}$ & $\begin{array}{c}836, \\
3\end{array}$ & $\begin{array}{c}441, \\
6\end{array}$ & 720 & $\begin{array}{c}938, \\
5\end{array}$ & $\begin{array}{c}794, \\
6\end{array}$ & & & & & \\
\hline D & & & & & & & & & & & & \\
\hline $\begin{array}{l}\text { Reciclá- } \\
\text { veis }\end{array}$ & & & & & & & & & & & & \\
\hline ES & & & & & & & & & & & & \\
\hline
\end{tabular}

\section{7 - Informações sobre coleta e transporte externo}

Empresas coletoras de serviços

\begin{tabular}{|l|l|l|l|}
\hline Nome da Empresa & \multicolumn{1}{|c|}{ CNPJ / CPF } & \multicolumn{1}{|c|}{$\begin{array}{l}\text { Tipos de resí- } \\
\text { duos }\end{array}$} & $\begin{array}{c}\text { Documentos le- } \\
\text { gais }\end{array}$ \\
\hline $\begin{array}{l}\text { Incinera Tratamen- } \\
\text { to de Resíduos } \\
\text { Ltda }\end{array}$ & $\begin{array}{l}07.393 .407 / 0001- \\
75\end{array}$ & $\begin{array}{l}\text { Resíduos de } \\
\text { saúde }\end{array}$ & $\begin{array}{l}\text { Contrato HMAB } \\
N^{\circ} 003 / 2010\end{array}$ \\
\hline
\end{tabular}

\section{Freqüência de coleta}

\begin{tabular}{|c|c|c|c|c|c|}
\hline $\begin{array}{c}\text { Tipos de } \\
\text { resíduos }\end{array}$ & $\begin{array}{c}\text { Diariamen- } \\
\text { te }\end{array}$ & $\begin{array}{c}\text { Dias alter- } \\
\text { nados }\end{array}$ & Semanal & $2 \times$ semana & $\begin{array}{c}\text { Outra fre- } \\
\text { qüência }\end{array}$ \\
\hline
\end{tabular}




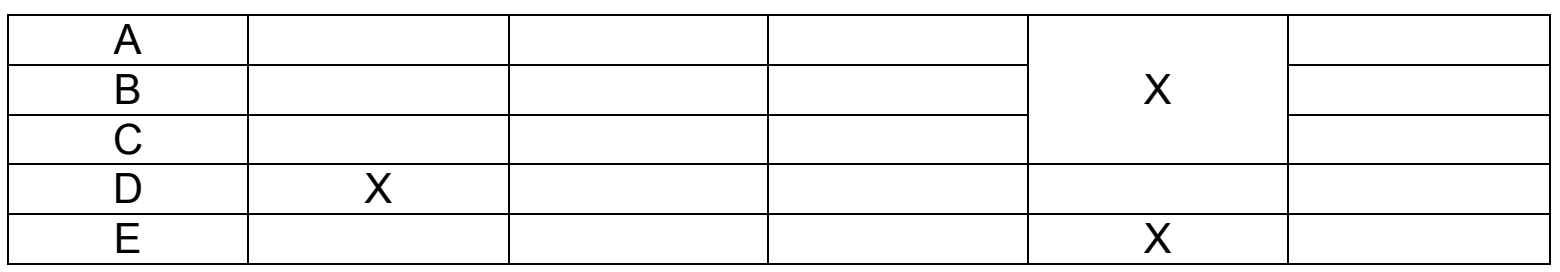

\section{Tipos de veículos utilizados na coleta}

\begin{tabular}{|c|c|c|c|c|c|}
\hline \multirow{2}{*}{$\begin{array}{c}\text { Tipos de } \\
\text { resíduos }\end{array}$} & \multicolumn{5}{|c|}{ Tipos de veículos } \\
\hline & Saveiro & Basculante & Baú & $\begin{array}{c}\text { Compacta- } \\
\text { dor }\end{array}$ & Outros \\
\hline A & & & \multirow{4}{*}{$\mathcal{*}$ X } & & \\
\hline B & & & & \\
\hline C & & & & & \\
\hline D & & & & & \\
\hline E & & & & & \\
\hline
\end{tabular}

\section{Tipos de tratamento interno e externo dos resíduos}

\begin{tabular}{|c|c|c|}
\hline \multirow[t]{2}{*}{ Grupos de resíduos } & \multicolumn{2}{|c|}{ Tipos de Resíduos } \\
\hline & Interno & Externo \\
\hline A & & \\
\hline SUB-GRUPO & & \\
\hline A1 & $\begin{array}{l}\text { SACO PLÁSTICO VERME- } \\
\text { LHO,LEITOSO (deverá ser } \\
\text { tratado fora da unidade, den- } \\
\text { tro de um sistema único da } \\
\text { Secretaria de Estado) }\end{array}$ & \multirow{5}{*}{ Incineração } \\
\hline A2 & $x x x x x x x$ & \\
\hline A3 & $\begin{array}{c}\text { SACO PLÁSTICO VERME- } \\
\text { LHO,LEITOSO }\end{array}$ & \\
\hline A4 & SACO BRANCO LEITOSO & \\
\hline A5 & $X X X X X X X$ & \\
\hline B & $\begin{array}{l}\text { - Substância perigosas (corrosi- } \\
\text { vas, reativas, tóxicas, explosivas } \\
\text { e inflamáveis): conforme reco- } \\
\text { mendações do fabricante para } \\
\text { acondicioná-los e descartá-los. } \\
\text { - Resíduos sólidos: recipientes } \\
\text { rígidos, adequados para cada } \\
\text { tipo de substância química, res- } \\
\text { peitadas as suas características } \\
\text { físico-químicas e seu estado } \\
\text { físico, identificados de acordo } \\
\text { com suas especificações. } \\
\text { - Resíduos para reciclagem ou } \\
\text { reaproveitamento: em recipien- }\end{array}$ & $\begin{array}{l}\text { Reciclagem ou Aterro Sa- } \\
\text { nitário ou Incineração }\end{array}$ \\
\hline
\end{tabular}




\begin{tabular}{|c|c|c|}
\hline & $\begin{array}{l}\text { tes individualizados: } \\
\text { *em recipientes rígidos, sempre } \\
\text { observando a compatibilidade } \\
\text { química dos componentes entre } \\
\text { si, como de cada resíduo com os } \\
\text { materiais da embalagem, evitan- } \\
\text { do reação química, enfraqueci- } \\
\text { mento ou deterioração da emba- } \\
\text { lagem, ou a permeabilidade aos } \\
\text { componentes do resíduo; identi- } \\
\text { ficados conforme lei. } \\
\text { *Embalagens primárias, secun- } \\
\text { dárias e os materiais contamina- } \\
\text { dos por substância química - } \\
\text { mesmo tratamento das substân- } \\
\text { cias químicas que as contamina- } \\
\text { ram. } \\
\text { *Embalagens secundárias, que } \\
\text { não entraram em contato com o } \\
\text { produto - fisicamente descarac- } \\
\text { terizadas e acondicionadas co- } \\
\text { mo resíduo do grupo D. } \\
\text { * Resíduos com mercúrio (Hg): } \\
\text { em recipientes sob selo d'água e } \\
\text { encaminhados para recupera- } \\
\text { ção. } \\
\text { Disquetes: reciclar o plástico e o } \\
\text { metal } \\
\text { *Cartuchos de impressão: recar- } \\
\text { ga, caso não haja possibilidade } \\
\text { de recarga => resíduo resíduo } \\
\text { do grupo D. } \\
\text { *Lâmpadas fluorescentes: sepa- } \\
\text { radas do restante dos resíduos } \\
\text { para serem enviadas à recicla- } \\
\text { gem }\end{array}$ & \\
\hline C & $X X X X X X X X$ & XXXXXXXX \\
\hline $\mathrm{D}$ & $\begin{array}{c}\text { SACOS PLÁSTICOS PRETOS, } \\
\text { IMPERMEÁVEIS. }\end{array}$ & \\
\hline $\mathrm{E}$ & $\begin{array}{l}\text { Recipiente rígido, estanque, } \\
\text { resistente à punctura, ruptura e } \\
\text { vazamento, impermeável, com } \\
\text { tampa, contendo a simbologia da } \\
\text { substância }\end{array}$ & Incineração \\
\hline
\end{tabular}

\section{9 - Informações sobre a destinação final dos resíduos}

\begin{tabular}{|c|c|c|c|c|c|}
\hline $\begin{array}{c}\text { Tipo de } \\
\text { disposição } \\
\text { final }\end{array}$ & $\begin{array}{c}\text { Empresa - } \\
\text { endereço }\end{array}$ & \multicolumn{4}{|c|}{ Grupo de resíduos } \\
\hline & & A & B & D & E \\
\hline
\end{tabular}




\begin{tabular}{|c|c|c|c|c|c|}
\hline $\begin{array}{l}\text { Incinera- } \\
\text { ção }\end{array}$ & $\begin{array}{c}\text { Incinera Tra- } \\
\text { tamento de } \\
\text { Resíduos } \\
\text { Ltda - Rua } \\
\text { Contorno } \\
\text { Oeste S/No } \\
\text { Qd } 04 \text { mod. } \\
08 \text { Polo } \\
\text { Couqueiro - } \\
\text { Senador } \\
\text { Canedo - } \\
\text { GO }\end{array}$ & $\begin{array}{l}\text { Incinera- } \\
\text { ção }\end{array}$ & $\begin{array}{c}\text { Reciclagem } \\
\text { ou Aterro } \\
\text { Sanitário } \\
\text { ou Incine- } \\
\text { ração }\end{array}$ & Incineração & Incineração \\
\hline
\end{tabular}

10 - Responsabilidades e qualificações das equipes de CCIH

\begin{tabular}{|c|c|c|c|}
\hline $\begin{array}{c}\text { Nome do Servi- } \\
\text { dor }\end{array}$ & Cargo & Formação & ART ou similar \\
\hline Cel Lemos & $\begin{array}{c}\text { Presidente da } \\
\text { CCIH }\end{array}$ & TC Teodoro & \\
\hline & & Maj Marco & \\
\hline & & Maj Portinho & \\
\hline & & Cap Med Virgínia Satuf & \\
\hline & & Cap Enf Maria Lúcia & \\
\hline & & Cap Farm Regina & \\
\hline & & Cap Farm França & \\
\hline & & Tem Enf Ruyblas & \\
\hline & & Tem Dent Juliana & \\
\hline & & $\begin{array}{c}\text { SC Enf Karla Kassan- } \\
\text { dra }\end{array}$ & \\
\hline
\end{tabular}

\section{1 - Capacitação de equipe de implantação do PGRSS}

\begin{tabular}{|c|c|c|c|}
\hline Nome do servidor & \multicolumn{2}{|c|}{ Treinamentos realizados } & \multirow{2}{*}{$\begin{array}{c}\text { Treinamentos a } \\
\text { realizar }\end{array}$} \\
\hline & Próprios & Terceirizados & \\
\hline Maj Kenia & \multirow{7}{*}{$\begin{array}{c}\text { 10/05/2010 - RDC } \\
\text { ANVISA 306/04 e Res } \\
\text { CONAMA 358/05 }\end{array}$} & \multirow{5}{*}{$\begin{array}{c}\text { Workshop: } \\
\text { Aplicação da } \\
\text { Política Nacio- } \\
\text { nal de Resí- } \\
\text { duos Sólidos } \\
\text { 11e } \\
\text { 12/12/2010 }\end{array}$} & \\
\hline Cap Lícia & & & \\
\hline $1^{\circ}$ Ten Marinho & & & \\
\hline $\begin{array}{l}1^{\circ} \text { Ten Thaís Ma- } \\
\text { dureira }\end{array}$ & & & \\
\hline $\begin{array}{l}2^{\circ} \text { Ten Canta- } \\
\text { nhede }\end{array}$ & & & \\
\hline $1^{\circ}$ Ten Lara & & & \\
\hline $2^{\circ}$ Ten Leyg Mei- & & & \\
\hline
\end{tabular}




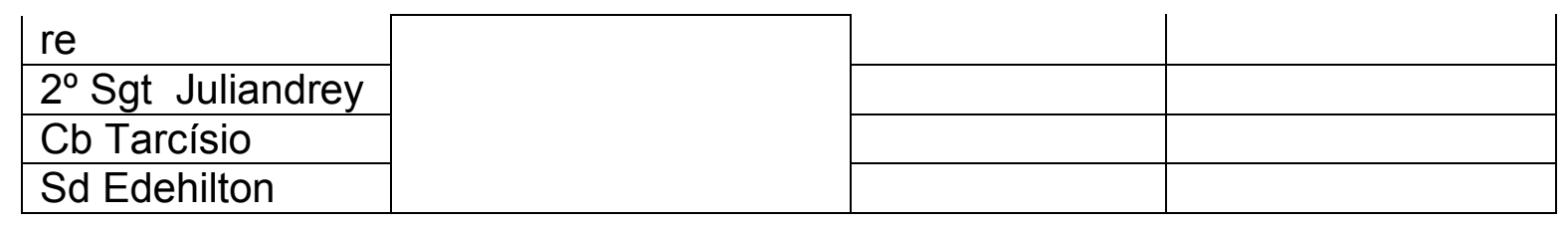

\section{1.a. TREINAMENTO EM SERVIÇO}

\begin{tabular}{|c|c|c|c|c|}
\hline TREINAMENTO & $\begin{array}{l}\text { PALESTRAN- } \\
\text { TE }\end{array}$ & DATA & $\begin{array}{l}\text { PÚBLICO } \\
\text { ALVO }\end{array}$ & $\begin{array}{l}\text { No DE PARTICl- } \\
\text { PANTES }\end{array}$ \\
\hline $\begin{array}{c}\text { RDC ANVISA } \\
\text { 306/04 e RES CO- } \\
\text { NAMA 358/05 }\end{array}$ & Maj Kenia & $10 \mathrm{MAI} 10$ & $\begin{array}{l}\text { Membros } \\
\text { da CGRSS }\end{array}$ & 08 \\
\hline $\begin{array}{l}\text { Palestra sobre Ge- } \\
\text { renciamento de } \\
\text { Resíduos de Servi- } \\
\text { ço de Saúde e } \\
\text { PGRSS }\end{array}$ & Maj Kenia & $13 \mathrm{MAI} 10$ & $\begin{array}{c}\text { Oficiais do } \\
\text { HMAB }\end{array}$ & \\
\hline $\begin{array}{c}\text { RDC ANVISA } \\
\text { 306/04 e RES CO- } \\
\text { NAMA 358/05 }\end{array}$ & $\begin{array}{l}\text { Dra Gleistone } \\
\text { M. de Souza }\end{array}$ & 17 MAI 10 & $\begin{array}{c}\text { Membros } \\
\text { da CGRSS }\end{array}$ & 09 \\
\hline PGRSS & $\begin{array}{l}\text { Dra Gleistone } \\
\text { M. de Souza }\end{array}$ & 03 NOV 11 & $\begin{array}{c}\text { Membros } \\
\text { da CGRSS } \\
\text { e equipe } \\
\text { de Enfer- } \\
\text { magem do } \\
\text { HMAB }\end{array}$ & 21 \\
\hline $\begin{array}{l}\text { Palestra sobre Ge- } \\
\text { renciamento de } \\
\text { Resíduos de Servi- } \\
\text { ço de Saúde e } \\
\text { PGRSS }\end{array}$ & Maj Kenia & 01 DEZ 10 & $\begin{array}{l}\text { Funcioná- } \\
\text { rios da Uni- } \\
\text { limps }\end{array}$ & 42 \\
\hline $\begin{array}{l}\text { Palestra sobre Ge- } \\
\text { renciamento de } \\
\text { Resíduos de Servi- } \\
\text { ço de Saúde e } \\
\text { PGRSS }\end{array}$ & Maj Kenia & 26 JUL 11 & $\begin{array}{l}\text { Funcioná- } \\
\text { rios da Uni- } \\
\text { limps }\end{array}$ & 29 \\
\hline & & & & \\
\hline & & & & \\
\hline & & & & \\
\hline
\end{tabular}

\section{2 - Indicadores indispensáveis para a avaliação do PGRSS}




\begin{tabular}{|c|c|c|}
\hline Item a ser avaliado & Indicadores & Resultados \\
\hline \multirow[t]{2}{*}{$\begin{array}{l}\text { Acidentes com perfu- } \\
\text { rocortantes }\end{array}$} & $\begin{array}{l}\text { Taxa de acidentes com perfurocor- } \\
\text { tantes em profissionais de limpeza }\end{array}$ & \\
\hline & $\begin{array}{l}\text { Total de acidentes com perfurocor- } \\
\text { tantes em profissionais de limpeza }\end{array}$ & \\
\hline \multirow[t]{3}{*}{ Geração de resíduos } & Variação da geração de resíduos & \\
\hline & $\begin{array}{l}\text { Total de resíduos gerados no perío- } \\
\text { do }\end{array}$ & \\
\hline & $\begin{array}{l}\text { Total de resíduos gerados atualmen- } \\
\text { te }\end{array}$ & \\
\hline \multirow[t]{3}{*}{ Resíduos do grupo A } & $\begin{array}{l}\text { Variação da proporção dos resíduos } \\
\text { do grupo A }\end{array}$ & \\
\hline & $\begin{array}{l}\text { Total de resíduos do grupo A gera- } \\
\text { dos }\end{array}$ & \\
\hline & Total de resíduos gerados & \\
\hline \multirow[t]{3}{*}{ Resíduos do grupo B } & $\begin{array}{l}\text { Variação da proporção dos resíduos } \\
\text { do grupo B }\end{array}$ & \\
\hline & $\begin{array}{l}\text { Total de resíduos do grupo B gera- } \\
\text { dos }\end{array}$ & \\
\hline & Total de resíduos gerados & \\
\hline \multirow[t]{3}{*}{ Resíduos do grupo C } & $\begin{array}{l}\text { Variação da proporção dos resíduos } \\
\text { do grupo C }\end{array}$ & \\
\hline & $\begin{array}{l}\text { Total de resíduos do grupo } \mathrm{C} \text { gera- } \\
\text { dos }\end{array}$ & \\
\hline & Total de resíduos gerados & \\
\hline \multirow[t]{3}{*}{ Resíduos do grupo D } & $\begin{array}{l}\text { Variação da proporção dos resíduos } \\
\text { do grupo D }\end{array}$ & \\
\hline & $\begin{array}{l}\text { Total de resíduos do grupo D gera- } \\
\text { dos }\end{array}$ & \\
\hline & Total de resíduos gerados & \\
\hline \multirow[t]{3}{*}{ Resíduos do grupo E } & $\begin{array}{l}\text { Variação da proporção dos resíduos } \\
\text { do grupo } \mathrm{E}\end{array}$ & \\
\hline & $\begin{array}{l}\text { Total de resíduos do grupo E gera- } \\
\text { dos }\end{array}$ & \\
\hline & Total de resíduos gerados & \\
\hline \multirow[t]{3}{*}{ Resíduos recicláveis } & $\begin{array}{l}\text { Variação da proporção dos resíduos } \\
\text { recicláveis }\end{array}$ & \\
\hline & Total de resíduos recicláveis & \\
\hline & Total de resíduos gerados & \\
\hline \multirow[t]{3}{*}{$\begin{array}{l}\text { Pessoas capacitadas } \\
\text { em gerenciamento } \\
\text { de resíduos }\end{array}$} & $\begin{array}{l}\text { Variação do percentual de pessoas } \\
\text { capacitadas em gerenciamento de } \\
\text { resíduos }\end{array}$ & \\
\hline & $\begin{array}{l}\text { Total de pessoas capacitadas em } \\
\text { gerenciamento de resíduos }\end{array}$ & \\
\hline & Total de pessoas capacitadas & \\
\hline Custo com RSS & $\begin{array}{l}\text { Variação da proporção de custo com } \\
\text { RSS }\end{array}$ & \\
\hline
\end{tabular}




\section{3 - Equipamentos necessários e recursos correspondentes}

\section{3.a) EQUIPAMENTO DE PROTEÇÃO INDIVIDUAL (EPI)}

- Uniforme: calça comprida e camisa com manga, no mínimo de tamanho $3 / 4$, de tecido resistente, de cor clara, específico para o uso do funcionário do serviço, de forma a identificá-lo de acordo com a sua função.

- Luvas: de PVC, impermeáveis, resistentes, de cor claras, preferencialmente brancas, antiderrapantes e de cano longo.

- Botas: de PVC, impermeáveis, resistentes, de cor clara, preferencialmente branca, com cano $3 / 4$ e solado antiderrapante.

- Gorro: de cor branca e de forma a proteger os cabelos.

- Máscara: Deve ser respiratória, tipo semifacial e impermeável.

- Óculos: deve ter lente panorâmica, incolor, ser de plástico resistente, com armação em plástico flexível, com proteção lateral e válvulas para ventilação.

- Protetor facial: quando necessário

- Avental: de PVC, impermeável, de comprimento abaixo dos joelhos e fechado ao longo de todo o seu comprimento.

\section{3.b) EQUIPAMENTO PARA ACONDICIONAMENTO DOS RSS}

$\mathrm{O}$ acondicionamento está diretamente relacionado à classificação. Segundo o que estabelece a NBR12.808/93 (assim como a NBR 9.190/93, NBR 9.191/02, NBR 9.195/93 e a NBR 13.506/93), os RSS serão acondicionados em:

- Saco branco: saco de plástico branco leitoso, resistente a ruptura e vazamento, resistente a ruptura e vazamento, impermeável, baseado na NBR 9.191/02 da ABNT e substitutivas, devidamente identificado com rótulo de fundo branco, desenho e contorno preto, contendo o símbolo universal de substância infectante e a inscrição "Risco Biológico" ou Infectante. As embalagens devem ser compatíveis com a sua capacidade e respeitados os limites de peso de cada saco e, ainda, ser compatível com a natureza química do produto a ser contido. É indispensável rotulagem contendo nome, simbologia, volume e data. O saco deve ser preenchido somente até $2 / 3$ de sua capacidade, sendo proibido o seu esvaziamento ou reaproveitamento.

- Saco vermelho: saco de plástico vermelho leitoso, resistente a ruptura e vazamento, resistente a ruptura e vazamento, impermeável, baseado na NBR 9.191/02 da ABNT e substitutivas, devidamente identificado com rótulo de fundo vermelho, desenho e contorno preto, contendo o símbolo universal de substância infectante e a inscrição "Risco Biológico" ou "Infectante". As embalagens devem ser compatíveis com a sua capacidade e respeitados os limites de peso de cada saco e, ainda, ser compatível com a natureza química 
do produto a ser contido. É indispensável rotulagem contendo nome, simbologia, volume e data. O saco deve ser preenchido somente até $2 / 3$ de sua capacidade, sendo proibido o seu esvaziamento ou reaproveitamento.

- Saco branco para resíduos do grupo B: saco de plástico branco leitoso, resistente a ruptura e vazamento, resistente a ruptura e vazamento, impermeável, baseado na NBR 9.191/02 da ABNT e substitutivas, devidamente identificado com rótulo de fundo branco, desenho e contorno preto, contendo o símbolo universal de substância infectante e a inscrição "Risco Químico". As embalagens devem ser compatíveis com a sua capacidade e respeitados os limites de peso de cada saco e, ainda, ser compatível com a natureza química do produto a ser contido. É indispensável rotulagem contendo nome, simbologia, volume e data. O saco deve ser preenchido somente até $2 / 3$ de sua capacidade, sendo proibido o seu esvaziamento ou reaproveitamento.

- Saco Preto: saco plástico preto, resistente, liso, impermeável.

- Recipientes para descarte de perfuro-cortantes: recipientes rígidos, resistentes à punctura, ruptura e vazamento, com tampa, devidamente identificados, sendo expressamente proibido o esvaziamento desses recipientes para o seu reaproveitamento.

- Lixeiras: para os sacos brancos e sacos vermelhos as lixeiras devem ser recipientes na cor branca, com tampa e pedal.

- Frascos para resíduos líquidos: resíduos líquidos devem ser acondicionados em frascos de até 02 (dois) litros, de material compatível com o líquido armazenado, de plástico ou vidro, conforme o caso, resistentes, rígidos e estanques, com tampa rosqueada e vedante.

- Containers: depósitos de polietileno, na cor branca, com tampa, de fácil higienização e manuseio.

\section{3. c) ORIENTAÇÕES - COLETA E TRANSPORTE INTERNO}

- A coleta interna consiste na retirada dos sacos de plástico de resíduos dos contenedores (cestos de plástico de resíduo), sua amarração e identificação com etiqueta de identificação, sua colocação no carro de coleta interna, segurando pela parte superior do saco, sem arrastar no chão, nem encostar e apoiar no corpo. Para esse processo é obrigatório o uso de Equipamentos de Proteção Individual (EPI's).

- Os EPl's não descartáveis, devem ser lavados e desinfetados diariamente ou sempre que entrar em contato com material infectante.

- Em caso de ruptura das luvas, o servidor deverá descartá-la imediatamente, não as reutilizando.

- Após a coleta interna, o servidor deverá lavar as mãos ainda enluvadas, retirando as luvas e descartando em local apropriado. As mãos devem ser higienizadas antes de colocar e após retirar as luvas.

\section{4 - PROGRAMA DE TREINAMENTO EM SERVIÇO}


A CGRSS mantém um programa de treinamento periódico que contempla os seguintes assuntos:

- Noções gerais sobre o ciclo da vida dos materiais;

- Conhecimento da legislação em vigor;

- Definições, tipo e classificação dos resíduos e potencial de risco dos mesmos;

- Sistema de gerenciamento adotado internamente no HMAB;

- Formas de reduzir a geração de resíduos;

- Conhecimento das responsabilidades e de tarefas;

- Reconhecimento dos símbolos de identificação das classes de resíduos;

- Conhecimento sobre a utilização dos veículos de coleta;

- Orientações quanto ao uso de Equipamentos de Proteção Individual - EPIs;

- Orientações sobre biossegurança e higiene pessoal;

- Providências a serem tomadas em caso de acidentes e de situações emergenciais

- Noções básicas de controle de infecção.

\section{4.a) ORIENTAÇÕES DIVERSAS}

As medidas de higiene e segurança permitem que o pessoal envolvido no Plano de Gerenciamento dos Resíduos Sépticos Sólidos - PGRSS, além de proteger sua própria saúde, possam desenvolver com maior eficiência seu trabalho, conhecer o cronograma de trabalho, sua natureza e responsabilidade, assim como, o risco a que estará exposto. As pessoas envolvidas com o PGRSS são submetidas a exames e avaliações:

Anamnese ocupacional;

Exame físico;

Exame mental;

Hemograma completo.

Vacinas exigidas:

Tétano;

Tuberculose;

Hepatite. 
- vacinar-se contra o tétano, tifo e hepatite B;

- submeter-se a um check-up que conste no mínimo de um exame para tuberculose

e contagem de hemoglobina para verificar seu bom estado de saúde;

- estar em perfeito estado de saúde, não ter problemas com gripes leves nem pequenas feridas na mão ou no braço;

- iniciar seu trabalho já devidamente protegido pelo equipamento pessoal - EPl's (luva em PVC - cano longo, máscara, óculos, avental

impermeável, bota em PVC - cano longo) para o caso de acidente com resíduos químicos;

- não comer, não fumar, nem mastigar qualquer produto durante o manuseio dos resíduos;

em caso de acidente em serviço:

- em caso de corte ou arranhão durante o manuseio dos resíduos, lavar a ferida com água e sabão imediatamente e ter acesso imediato ao PAM;

- registrar sempre o acidente ocorrido no manuseio dos resíduos;

- ter sempre sacos de reserva para uso imediato quando do rompimento para não deixar restos no chão;

- descartar imediatamente as luvas em caso de ruptura, não as reutilizando;

- lavar e desinfetar o equipamento de proteção pessoal, especialmente as luvas, após término do trabalho e,

- tomar banho, no local de serviço, após a jornada de trabalho.

\title{
15 - Referência Bibliografia
}

- Manual de gerenciamento de resíduos de serviços de saúde / Ministério da Saúde, Agência Nacional de Vigilância Sanitária. - Brasília : Ministério da Saúde, 2006.

- RESOLUÇAO CONAMA - 358/2005

- RDC 306/2004)

\section{6 - CONSIDERAÇÕES FINAIS}

Este estabelecimento se compromete a seguir as disposições e implantar as medidas contidas neste plano.

\author{
PAULO SÉRGIO IGLESSIAS - CEL MED
}

DIRETOR DO HMAB 